\title{
The inflammatory transcriptome of reactive murine astrocytes and implications for their innate immune function
}

\author{
Jeppe Falsig, ${ }^{*},+, 1,2$ Peter Pörzgen, ${ }^{*}, 1$ Søren Lund,* André Schrattenholzł and Marcel Leist* \\ *H. Lundbeck A/S, Valby, Denmark \\ $\dagger$ Department of Neuropathology, University of Zürich, Switzerland \\ $\ddagger$ ProteoSys AG, Mainz, Germany
}

\begin{abstract}
Upon injury, astrocytes assume an activated state associated with the release of inflammatory mediators. To model this, we stimulated murine primary astrocytes with a complete inflammatory cytokine mix consisting of TNF- $\alpha, \mathrm{IL}-1 \beta$ and IFN- $\gamma$. We analysed the transcriptional response of 480 genes at 4 and $16 \mathrm{~h}$ after stimulation on a chip designed to give a representative overview over the inflammation-relevant part of the transcriptome of macrophage-like cells. The list of the 182 genes found to be significantly regulated in astrocytes revealed an intriguing co-ordinate regulation of genes linked to the biological processes of antiviral/antimicrobial defence, antigen presentation and facilitation of leucocyte invasion. The
\end{abstract}

Astrocytes are a heterogeneous CNS-specific cell population with a housekeeping function of regulating the homeostasis of the brain, i.e. the composition of the extracellular fluid, energy storage, and uptake of nutrients over the blood-brain barrier (BBB) (Kettenmann and Ransom 2004). In disease and injury situations, astrocytes can be activated and take on a variety of new roles. For example, activated astrocytes become part of the innate immune response of the brain and produce a large variety of different mediators normally known to be secreted from activated macrophages (Aloisi 2001). They can also form a link between the innate and adaptive immune response by processing and presenting antigens to $\mathrm{T}$ cells, and by their involvement in mononuclear leucocyte migration into the brain (Fontana et al. 1984; Babcock et al. 2003). It has been postulated that astrocytes can induce opening of the BBB during non-traumatic disease (i.e. without an acute opening of the BBB) leading to an infiltration of the brain by peripheral immune cells (Proescholdt et al. 1999). Astrocytes are known to play a role in microglia activation and vice versa (Bezzi et al. 2001). These processes are particularly well documented in autoimmune latter group was characterized by very high up-regulations of chemokine genes. We also identified regulations of a thymidylate kinase and an interferon-regulated protein with a tetratricopeptide motive, both up to now only known from macrophages. The transcriptional regulations were confirmed on the protein level by a proteomic analysis. These findings taken together suggest that activated astrocytes in brain behave similarly in many respects to inflamed macrophages in the periphery.

Keywords: chemokines, gene regulation, inflammation, neuroimmunology, proteomics.

diseases, such as multiple sclerosis, or in paraneoplastic neurological degenerations, but it is now being recognized that infiltration of immune cells may also take place in chronic or acute neurodegenerative disorders (Babcock et al. 2003; McGeer and McGeer 2003; Roberts and Darnell 2004; Heppner et al. 2005). This implicates astrocytes as potential co-ordinators of an injury response, together with microglia. Furthermore, in the recovery phase after an acute

Received August 22, 2005; revised manuscript received October 24, 2005; accepted November 2, 2005.

Address correspondence and reprint requests to Jeppe Falsig, Institute of Neuropathology, University of Zürich, Schmelzbergstrasse 12, CH-8032 Zürich, Switzerland. E-mail: jeppefalsig.pedersen@usz.ch

${ }^{1}$ Jeppe Falsig and Peter Pörzgen contributed equally to this work.

${ }^{2}$ Jeppe Falsig is supported by a grant from Zürich Neurowissenschaftliches Zentrum.

Abbreviations used: BBB, blood-brain barrier; CCM, complete cytokine mix; GFAP, glial fibrillary acidic protein; IV, index of variance; NOS, nitric oxide synthase; PAI-1, plasminogen activation inhibitor 1; PBS, phosphate-buffered saline; PBS-G, PBS with $2 \mathrm{~g} / \mathrm{L}$ glucose; Q-PCR, quantitative PCR; Tc, threshold cycle. 
neurodegenerative insult, astrocytes play a role by forming a glial scar with all its positive and negative implications (Bush et al. 1999; Faulkner et al. 2004). Glial fibrillary acidic protein (GFAP) is the commonly, and nearly exclusively, used activation marker of astrocytes in vivo. However, it is not clear whether GFAP expression correlates with any particular transcriptional profile of astrocytes, and how a reactive astrocyte can be defined. In vivo and in vitro studies indicate that astrocytes may assume multiple different activation states depending on disease setting, stimulation and timing (Eddleston and Mucke 1993). Moreover, some components of the activation may be blocked without effect on others (Falsig et al. 2004b), which further increases the multitude of possible inflammatory patterns. Both for the understanding of the role of astrocytes in pathophysiology and for the design of pharmacological agents affecting astrocytes, it is highly desirable to define some activation states more comprehensively.

Despite the prominent role of astrocytes and many in-depth studies examining individual pathways or small groups of up to two dozen genes, we have found only a few publications that have addressed a broader characterization of the response of activated astrocytes. To our knowledge, two studies have addressed the response to JC or HIV viral infection (Radhakrishnan et al. 2003; Kim et al. 2004), another investigated the response to astrocytic differentiation factors (Bachoo et al. 2004) and three studies have centred on cytokine-stimulated human astrocytes. One (Meeuwsen et al. 2003) of these examined 268 inflammation-linked genes in adult astrocyte cultures and the others (John et al. 2002; Rivieccio et al. 2005) used a large $10 \mathrm{~K}$ or $28 \mathrm{~K}$ array to investigate the response of fetal cells. The general reaction pattern of human astrocytes has been excellently reviewed by John et al. (2005).

We have previously characterized basic parameters of a rodent model system using a cytokine mix consisting of the two microglial cytokines, TNF- $\alpha$ and IL- $1 \beta$, and the T/NKcell cytokine, IFN- $\gamma$, to stimulate primary cultures of murine astrocytes (Falsig et al. 2004a). This model recapitulates many aspects of a reactive astrocytosis and has been used by us and others to study astrocytic cytokine signalling (Castano et al. 2002; Oberdorfer et al. 2003; Falsig et al. 2004b). Although most basic immunological pathways are well conserved between rodent and man, there are some striking differences important for understanding the many murine model systems of disease pathogenesis used in biomedical research. For instance, it is known that human IL-8 has no direct mouse homologue (Simonet et al. 1994); conversely the stress-induced murine caspase 12 is found only in a small human sub-population (Saleh et al. 2004), and the regulation of inducible nitric oxide synthase in particular seems to be entirely different between man and rodent (Aktan 2004). In order to obtain robust baseline data on the activation pattern of cytokine-stimulated murine astrocytes, we set out to analyse the inflammation-specific transcriptional response of this glial population. We hope that this information contributes to the understanding of the role of astrocytes in murine disease models and cell interaction networks. Our set of 480 genes was compiled from an exploratory quantitative massspectrometry analysis to identify new regulated proteins, the literature on gene regulation in astrocytes or microglia in various disease models, and genes found to be regulated in a study of neonatal hypoxia (Hedtjarn et al. 2004).

\section{Materials and methods}

\section{Materials}

Complete cytokine mix (CCM) contained $10 \mathrm{ng} / \mathrm{mL}$ murine TNF- $\alpha$, $10 \mathrm{ng} / \mathrm{mL}$ murine IL-1 $\beta$ (Sigma-Aldrich, Copenhagen, Denmark) and $5 \mathrm{U} / \mathrm{mL}$ recombinant murine IFN- $\gamma$ (R \& D Systems, Abingdon, UK). CEP-1347 (3,9-Bis[(ethylthio)methyl]-K-252a) was synthesized at Cephalon (West Chester, PA, USA). Basic laboratory chemicals and inhibitors were purchased from Sigma unless stated otherwise.

\section{Primary astrocyte cultures}

Pregnant C57bL/6jbom mice were purchased from Harlan (Horst, The Netherlands). All experimental procedures were carried out in accordance with the directives of the Danish National Committee on Animal Research Ethics and the European Communities Council Directive \#86/609 for care of laboratory animals.

Primary cortical astrocytes were prepared from 1-2-day-old mice according to a slightly modified version of a protocol by Weinstein (1997). In brief, brains from six pups were removed and kept on ice in a phosphate-buffered saline (PBS) buffer containing $2 \mathrm{~g} / \mathrm{L}$ glucose and $0.001 \%(\mathrm{w} / \mathrm{v})$ phenol red, $\mathrm{pH} 7.4$ (PBS-G). The cortices were dissected out, and hippocampi and meninges were carefully removed before digestion in PBS-G containing $10 \mathrm{mg} / \mathrm{mL}$ trypsin TRL (Worthington, Lakewood, NJ, USA), $1 \mathrm{mg} / \mathrm{mL}$ DNase (Worthington) and $5 \mathrm{mg} / \mathrm{mL} \mathrm{MgSO}_{4}$, for $3 \mathrm{~min}$ at $37^{\circ} \mathrm{C}$. Tissue was washed in PBS-G and triturated in PBS-G with $0.5 \mathrm{mg} / \mathrm{mL}$ DNase using, sequentially, an 18,20 and 23 Guage needle. Cells were filtered through a $70 \mu \mathrm{m}$ mesh (BD Biosciences, Brøndby, Denmark), pelleted (150 $\mathrm{g}$ for $5 \mathrm{~min}$ ), and re-suspended in PBS-G containing DNase and $\mathrm{MgSO}_{4}$. Cells were carefully layered over a 30\% Percoll solution (Amersham Pharmacia Biotech, Hørsholm, Denmark) in PBS-G and centrifuged at $150 \mathrm{~g}$ for $10 \mathrm{~min}$. Cells were recovered from the interface, washed once with $15 \mathrm{~mL}$ PBS-G (100 $\mathrm{g}$ for $5 \mathrm{~min}$ ) and re-suspended in Dulbecco's modified Eagle's medium (DMEM) (high glucose), 10\% fetal calf serum (FCS), $100 \mathrm{U} / \mathrm{mL}$ penicillin and $100 \mu \mathrm{g} / \mathrm{mL}$ streptomycin. This medium was used for growing cells. However, for all experiments, cells were changed to medium containing $2 \%$ FCS. All medium constituents were purchased from Invitrogen (Taastrup, Denmark). Cells were counted in a trypan blue solution to assess viability, and seeded at a density of 10000 cells $/ \mathrm{cm}^{2}$ in $185 \mathrm{~cm}^{2}$ flasks (all dishes used were from Nunc, Roskilde, Denmark). The medium was changed after 3 days and subsequently, twice a week. Cells were trypsinized and re-seeded after 14 days in primary culture, and were always used for experiments 6-8 days after re-plating. 


\section{Standard cell incubation scheme}

Cells were treated with a previously characterized cytokine mix (CCM) which we used as an artificial approximation to an inflammatory condition (Falsig et al. 2004a). After 24 h, cells were lysed for protein analysis, and nitrite accumulation in medium was measured to control for appropriate stimulation of cells. For mRNA expression studies, two time points, $4 \mathrm{~h}$ and $16 \mathrm{~h}$, were chosen based on previous experience (Falsig et al. 2004a,b,c). For analysis of signal transduction, signal-modulatory compounds were added 30 min prior to CCM stimulation.

\section{Immunocytochemistry}

Astrocytes were seeded on plastic and stained at $25^{\circ} \mathrm{C}$ as follows. The cells were washed once with PBS and fixed in $4 \%$ paraformaldehyde for $12 \mathrm{~min}$. After three washes with PBS, the coverslips were blocked for $30 \mathrm{~min}$ in PBS $/ 0.05 \%$ Tween (PBS/Tween) containing $5 \%$ FCS and then incubated for 45 min with mouse IgG anti-GFAP clone G-A-5 (Sigma-Aldrich, Copenhagen, Denmark) 1:1000, mouse IgG1 anti- $\beta$ III-tubulin (Chemicon, Hampshire, UK) $1: 500$, rat anti-CD31 IgG2a $1: 1000$, rat IgG2a anti-MBP Clone 12 (both Serotec, Hamar, Norway) $1: 500$, and Phalloidin-Texas Red $(100 \mathrm{~nm})$ and Isolectin- $\mathrm{B}_{4}$ Griffonia simplicifolia $(2 \mu \mathrm{g} / \mathrm{mL})$ (both Molecular Probes, Eugene, OR, USA) in blocking buffer. The cells were washed three times in PBS/Tween and incubated with Alexa Fluor 488 goat anti-mouse or rat $\operatorname{IgG}(6 \mu \mathrm{g} / \mathrm{mL})$ in blocking buffer, and dye Hoechst-33342 $(1 \mu \mathrm{g} / \mathrm{mL})$ (both purchased from Molecular Probes, Eugene, OR, USA), for $30 \mathrm{~min}$.

\section{Nitrite measurement}

Nitrite was measured using the Griess reagent. In brief, $50 \mu \mathrm{L}$ supernatant fluid or $\mathrm{NaNO}_{2}$ standards were mixed with $25 \mu \mathrm{L} \mathrm{N}$-(1naphthyl)ethylenediamine $\left(0.1 \%\right.$ in $\left.\mathrm{H}_{2} \mathrm{O}\right)$ and $25 \mu \mathrm{L}$ sulfanilamide $(1 \%$ in $1.2 \mathrm{~N} \mathrm{HCl})$ in a $96-w e l l$ plate. After $3 \mathrm{~min}$, samples were read at $(570-690 \mathrm{~nm})$.

\section{Transcript analysis by oligonucleotide hybridization analysis}

We selected a list of 480 murine genes with a known or suspected role in neuroinflammation and glia activation. For each of these genes, one oligonucleotide (40-50mer) was designed by MWG (MWG, Ebersberg, Germany) using their proprietary OLIGO4ARRAY software and CodeSeq database, which selects the oligos preferentially from the 3 '-region of each coding sequence. Furthermore, each oligomer was scrutinized to meet physicochemical parameters (such as melting temperature, self-complementarity, secondary structure) and extensively tested to minimize cross-hybridization to other sequences of the mouse genome in silico. All oligos were synthesized using MWG's high purity salt free (HPSF) technology followed by Matrix assisted laser desorption/ionizationtime of flight (MALDI-TOF) quality control.

The oligomeres were spotted onto activated glass slides (Pan Epoxy, MWG or CodeLink, Amersham) using a 417 Affymetrix 'ring and pin' spotter. Sample preparation and labelling was carried out as described in protocols on Joseph DeRisi's website (http:// www.microarrays.org/protocols.html) in (Hughes et al. 2001) and protocols available from MWG-Biotech (http://www.MWGbiotech.com). In brief, $5 \mu \mathrm{g}$ total RNA were reverse-transcribed using a $\left[\left(\mathrm{dT}_{24}\right) \mathrm{T} 7 \text { promotor }\right]_{65}$ primer for the first-strand synthesis, followed by a second-strand synthesis according to the manufac- turer's protocol (cDNA Synthesis System; Roche Diagnostics, Indianapolis, IN, USA). The resulting (double-stranded) dsDNA was purified using Roche's High Pure RNA Tissue Kit. The purified dsDNA was amplified using Ambion's MEGAscriptT7 kit (Ambion, Austin, TX, USA) and included the incorporation of aminoallyl-modified UTP (aa-UTP). The reaction mix contained the following concentrations of nucleotides: $7.3 \mathrm{~mm} \mathrm{ATP,} \mathrm{CTP} \mathrm{and}$ GTP, $3.6 \mathrm{~mm}$ UTP and $4.7 \mathrm{~mm}$ aa-UTP (Sigma), and was incubated for $16 \mathrm{~h}$ at $37^{\circ} \mathrm{C}$. The amplified RNA was purified using Roche's High Pure RNA Tissue Kit and, subsequently, its concentration and purity was controlled by spectrophotometric analysis. We usually obtained 30-50 $\mu$ g amplified cRNA from a starting material of $5 \mu \mathrm{g}$ total RNA. Then, $10 \mu \mathrm{g}$ of the aminoallylmodified cRNA were coupled to the $N$-hydroxy-succinimidyl esters of the Cy3 or Cy5 dyes following Joe de Risi's protocol (http:// www.microarrays.org/pdfs/amino-allyl-protocol.pdf). The dye esters were from Amersham ( $\mathrm{Cy} 3$ or $\mathrm{Cy} 5$ mono-Reactive dye). The labelled cRNA was then purified from the excess dye using Qiagen's RNeasy Mini columns and their 'RNA clean-up' protocol (Qiagen, Valencia, CA, USA). Finally, in order to perform a 'dyeswap' experiment, the labelled cRNA samples were split into two equal aliquots and combined with the complimentary-labelled samples of a second cRNA preparation (e.g. Cy3-vehicle vs. Cy5CCM and Cy5-vehicle vs. Cy3-CCM). Before hybridization, the combined and labelled cRNA samples were submitted to a mild alkaline fractionation step at $94^{\circ} \mathrm{C}$ for $15 \mathrm{~min}$ in $4 \mathrm{~mm}$ Tris acetate ( $\mathrm{pH}=8.1$ ), $3 \mathrm{~mm} \mathrm{MgAc}$ and $10 \mathrm{~mm} \mathrm{KAc}$, quickly followed by rebuffering and concentration using Microcon YM-10 spin filters (Millipore, Copenhagen, Denmark) and a speed-vac centrifuge. The Cy-labelled cRNAs were dissolved in Gene Frame Hybridization buffer (MWG Biotech) and denatured for $5 \mathrm{~min}$ at $90^{\circ} \mathrm{C}$ before incubation on the microarray slides for $16 \mathrm{~h}$ at $42^{\circ} \mathrm{C}$. Washing was carried out in three steps of increasing stringency: $2 \times$ saline sodium citrate (SSC) buffer, $0.1 \%$ sodium dodecyl sulfate (SDS) followed by $1 \times \mathrm{SSC}, 0.01 \% \mathrm{SDS}$ and $0.5 \times \mathrm{SSC}$ (all solutions were preheated to $30^{\circ} \mathrm{C}$ ). Finally, each slide was spun dry and scanned in a 428 Affymetrix confocal laser scanner (Santa Clara, California, USA) at three different intensities (photo multiplier gains).

The microarrays were analysed using IMAGENE 4.2 (BioDiscovery Inc., El Segundo, CA, USA) for spot location, array alignment and background subtraction. Signal intensities for individual spots were adjusted for local background. Microsoft Excel was used for further statistical analysis of the IMAGENE output files. For example, $\mathrm{Cy} 3 / \mathrm{Cy} 5$ ratio normalization was carried out by multiplying each ratio value with a scaling factor that was defined as the ratio of the overall signal intensity of the Cy5 versus Cy3 channel (Knudsen 2002). Each microarray experiment was performed at least twice independently. To further account for bias introduced by dye bleaching or labelling, each experiment was carried out as a dyeswap with the resulting ratio value being the arithmetical mean from two slides of opposite labelled sample pairs. Genes with very low signal intensities (less than fivefold of the background) were excluded from the analysis. The statistically significant cut-offs for the Neuroflame chip were determined by validation experiments. Two similar RNA samples were hybridized against one another on six chips and the cut-offs for false-positives were determined, on the basis of these data and a statistical routine calculation, to be $1.9 / 0.6$-fold with a $p$-value of $<0.01$. 


\section{Quantitative PCR}

Cells stimulated in $10 \mathrm{~cm}$ dishes were washed once with PBS and total RNA was extracted using TRIzol reagent (Invitrogen) according to the manufacturer's protocol. Purified RNA was treated with DNA-free, DNase-1 (Ambion, Huntingdon, UK) according to the manufacturer's protocol. Total RNA $(1 \mu \mathrm{g})$ was reversetranscribed with TaqMan RT-Reagent (Applied Biosystems, Nærum, Denmark), using random hexamers in a $100 \mu \mathrm{L}$ reaction, on a PTC200 DNA Engine Thermal Cycler (VWR International, Albertslund, Denmark), according to a programme of $10 \mathrm{~min}$ annealing at $25^{\circ} \mathrm{C}$, $30 \mathrm{~min}$ reverse transcription at $48^{\circ} \mathrm{C}, 5 \mathrm{~min}$ inactivation at $95^{\circ} \mathrm{C}$. The cDNA was quantified using the SYBR GREEN PCR Master Mix kit (Applied Biosystems). Each reaction contained $2.5 \mu \mathrm{L}$ cDNA of the $100 \mu \mathrm{L}$ RT product, $300 \mathrm{~nm}$ forward and reverse primers, $12.5 \mu \mathrm{L}$ master mix and $7 \mu \mathrm{L}$ water in a total volume of $25 \mu \mathrm{L}$. PCR amplification was run in a 96-well experimental plate format on an iCycler Thermal Cycler equipped with iCycler Optical System (Bio-Rad, Hercules, CA, USA). The programme set-up was $10 \mathrm{~min}$ at $95^{\circ} \mathrm{C}, 40$ cycles of $15 \mathrm{~s}$ at $95^{\circ} \mathrm{C} / 1 \mathrm{~min}$ at $60^{\circ} \mathrm{C}$. A melting curve was obtained to verify the measured signal and the product was run on a $4 \%$ agarose gel to verify the presence of only one band. Quantification was performed as follows. Using the iCycler data analysis software (Bio-Rad), the threshold cycle (Tc) was determined for each sample. Tc was defined as the cycle at which the level of fluorescence increased significantly above the background levels of fluorescence. The concentration of cDNA was calculated by comparing $\mathrm{Tc}$ of samples with Tcs of a standard curve. The standard curve was obtained by a serial dilution of cDNA. Each sample was run in two reactions, one with the primer set of interest and one with a GAPDH primer set; all data are displayed as the ratio between the calculated starting concentration of the cDNA of interest and GAPDH. All primers except the housekeeping gene GAPDH were intron spanning in order to distinguish cDNA from genomic DNA. For GAPDH, the order of magnitude between the samples and the samples without reverse transcriptase was above $10^{6}$. Primers used were GAPDH sense (Acc. no. NM_008084): 5'-TGCACCACCAACTGCTTAG-3', antisense: 5'-GGATGCAGGGATGATGTTC-3'; IFIT-3 sense (Acc. no. BC_003804): 5'-GGCTGAATGGTTTTGGGGTTTG-3', antisense: 5'-CAGGTTCATGGTGCCAGGAAAA-3'; PAI-1 sense (NM_008871): 5'-GCAACCCTGGCCGACTTCA-3', antisense 5'-ACGCCACTGTGCCGCTCTC3'; MCP-1 sense (NM_011333): 5'-CATGCTTCTGGGCCTGCTGTTC-3' , antisense, 5'-CCTGCTGCTGGTGATCCTCTTGTAG-3'; RANTES sense (NM_013653): 5-GCAGCTGCCCTCACCATCATC-3', antisense 5-GAGGCAGCGCGAGGGAGAG-3'; TYKi sense (Acc. no. NM_020557): 5'-GGATGCGCTGCACACCAATT3', antisense: 5'-TAGCTCCTTGGCCTCCGTTGG-3'. Primers were designed using DNA-STAR software package (DNASTAR Inc, Madison, WI, USA) and all primers were blasted using BLASTn (http://www.ncbi.nlm.nih.gov/BLAST/).

\section{Proteomics analysis}

Primary astrocytes were seeded in $175 \mathrm{~cm}^{2}$ flasks and treated with $\mathrm{CCM}$ for $24 \mathrm{~h}$. For cell harvest, plates were washed twice with icecold PBS and then scraped off with a cell scraper in $1 \mathrm{~mL}$ lysis buffer ( $2 \%$ SDS; $0.1 \mathrm{~m}$ Tris pH 8.8). Alkylation (for introduction of the iodine isotopes) and sample treatment were performed exactly as described (Vuong et al. 2000; Cahill et al. 2003).
The differential and quantitative protein expression analysis was performed by the ProteoTope method (Cahill et al. 2003), which is based on radioiodination, 2D-polyacrylamide gel electrophoresis (2D-PAGE) and high sensitivity radio ratio-imaging. In brief, small amounts of each sample were labelled with ${ }^{125}$ I and ${ }^{131}$ I for differential pattern control. The signals from these two isotopes were distinguished in one 2D-PAGE gel to generate a quantitative multi-colour differential display of proteins. A direct comparison of digitized integrated spot intensities for the samples run on one gel was used for further analysis. These experiments were always run in parallel with a dye (= isotope) swap as duplicates. In parallel, silver-stained gels were produced for spot picking and protein identification, and for complementary quantification. In general, a spot was selected for further analysis if the $t$-test probability was higher than $95 \%$ and the expression ratio higher than 1.5 . At that point, the image quality was checked to assure that the spot was consistently detected on all images. Protein identification was based on different mass spectrometric methods. Briefly, gel plugs of selected protein spots were excised and the proteins contained in the gel plugs digested using trypsin. The resulting solution was analysed first with a high throughput peptide mass fingerprint procedure based on MALDI-TOF-MS. For those spots where no unambiguous identification was achieved, a fragment ion analysis based on LC-ESI-IonTrap-MS/MS was added (Cahill et al. 2003). For the identification of the proteins, the peptide masses extracted from the mass spectra were searched against the NCBI non-redundant protein database (http://www.ncbi.nlm.nih.gov) using MASCOT software version 1.9 (Matrix Science, London, UK).

\section{Enzyme-linked immunoassays}

Astrocytes were seeded at a density of 10000 cells per well and after 7 days in vitro, CCM was added in a volume of $100 \mu \mathrm{L}$. After $24 \mathrm{~h}$, RANTES was measured in the supernatant fluid using the murine-specific Quantikine M kit (R \& D Systems, Abingdon, UK) according to the manufacturer's instructions.

\section{Statistics}

For the transcript analysis, two sets of biological samples were measured at the $4 \mathrm{~h}$ time point and three sets at the $16 \mathrm{~h}$ time point. Results are displayed as the average of the measurements (including dye swap experiments) \pm index of variance (IV). IV was calculated as the standard deviation of all individual measurements (four and six replicates, respectively, at 4 and 16 h). For quantitative PCR and ELISA, results are displayed as means \pm SD of triplicates. Only data from biological experiments confirmed at least once independently are displayed. One-way analysis of variance followed by the Dunnett's test was used for statistical evaluation $\left({ }^{*} p<0.05\right.$, $* * * p<0.001)$. All primary chip data will be made freely accessible in MIAME format, or can be directly viewed/downloaded in semiprocessed form from the website: http://www.public-results.com.

\section{Results}

\section{Culture characterization}

The cultures were characterized by immunocytochemical and functional biochemical methods for their content of astrocytes (GFAP), oligodendrocytes (MBP, galactocerebroside), 
endothelial cells (Pecam-1), fibroblasts (Phalloidin), neurones ( $\beta$ III-tubulin) and microglia (Isolectin- $\left.\mathrm{B}_{4}\right)$. We failed to find any Pecam-1- and $\beta_{\mathrm{III}}$-tubulin-positive cells, but a few Phalloidin-positive cells with a morphology resembling fibroblasts were detected (far below 1\%). As described extensively before (Falsig et al. 2004a), the cultures contained a homogeneous astrocyte population constituting at least $98 \%$ of the cells, and the microglial contamination was below our detection limit (by functional assays or staining). We also performed a base line analysis of expressed proteins to obtain a protein signature of the cultures. Lysates from non-stimulated cultures were separated on $2 \mathrm{D}$ gels, and a computer-driven system performed a random selection and automatic mass-spectrometry sequencing of 98 most abundant proteins spread out evenly over the entire gel range. The protein pattern identified reflects the standard metabolic role of astrocytes in the brain. Many proteins were involved in glycolysis, glycogen regulation, neurotransmitter metabolism and cellular metabolism (31 proteins) (see supplementary fig. S1). Also, various proteasome subunits, ER-chaperones, lipid-binding factors, antioxidant molecules, transcription factors, signalling molecules and, in particular, proteins related to the regulation of the cytoskeleton (18 proteins) were identified. These proteins include astrocyte markers such as Purine-nucleoside phosphorylase and GFAP and present a first, albeit limited protein signature of cultured astrocytes.

\section{Proteomic analysis of activated astrocytes}

In order to explore the response of murine astrocytes to inflammation, primary cultures were stimulated with a complete cytokine mix (CCM) of TNF- $\alpha$, IFN- $\gamma$ and IL-1 $\beta$ as described (Falsig et al. 2004a,b). We have previously shown that there are major synergistic stimulatory effects when the three cytokines present in an inflammatory lesion are used as in this study (Falsig et al. 2004a). Initially, we performed an exploratory proteomic analysis of cytokinestimulated astrocyte cultures in the hope of finding new proteins not previously associated with astrocyte activation. We used a radioactive protein labelling method for a quantitative and differential analysis of proteins up-regulated following $24 \mathrm{~h}$ of CCM treatment. Lysates from control and CCM-stimulated cells were labelled with ${ }^{125} \mathrm{I}$ and ${ }^{131} \mathrm{I}$ isotopes; samples were then mixed, separated by 2D-PAGE and analysed for protein spots with differential isotope abundance at a confidence interval above $95 \%$. Seven proteins were identified by this method with an abundancy ratio ranging from 1.5 (CLIC4) to $>25$ (IFIT3) and identified by mass spectrometry (Fig. 1a).

In a parallel approach, we used silver-stained gels for identification and quantification of regulated proteins (example in Fig. 1b). Here, 12 proteins were identified, two of which were previously identified by the ProteoTope method (TYKi and PA28 $\alpha$ ) (Fig. 1a). We were particularly intrigued by the discovery of the strong regulation of TYKi and IFIT-3, since these may have the potential to be used as new inflammation markers in the brain (very low basal expression, intracellular localization).

\section{Global transcriptional response pattern over time}

Next, we examined the temporal response of murine astrocytes to cytokine stimulation using oligonucleotide hybridization analysis. The time points for analysis were chosen at $4 \mathrm{~h}$ after stimulation (peak of primary response wave) and at $16 \mathrm{~h}$ after stimulation (secondary responses and potential down-regulations). At these times we prepared total RNA samples that were processed and used for oligonucleotide hybridization analysis. Of the 480 genes on our customspotted array (see supplementary Fig. S2 for all genes present on the array), we found that $38 \%$ (=182 genes) were regulated significantly, i.e. with a ratio above 1.9 or below 0.6 at least at one of the time points. The majority of regulated genes were expressed higher in stimulated astrocytes than in controls (137 genes). Of these, $82(60 \%)$ were up-regulated at both time points, while 21 were up-regulated only after $4 \mathrm{~h}$, and 29 only after $16 \mathrm{~h}$. Of the 45 downregulated genes, 19 (42\%) were down-regulated at both time points. Twenty-four genes were only down-regulated after $16 \mathrm{~h}$ and two were down-regulated only after $4 \mathrm{~h}$. This high percentage of regulated genes reflects our pre-selection of genes known or assumed to be related to glial or macrophage activation, and the general response pattern of the murine astrocytes was similar to a fulminant inflammatory response of macrophages. Notably, tyk-i and ifit-3 were also detected by the transcription profiling to be strongly regulated, so that the up-regulated protein levels seem to correlate well with de novo transcription-translation (Fig. 1a).

Genes involved in cell death, cell cycle and cellular stress To facilitate interpretation of the general response pattern, we manually grouped genes according to their best-characterized biological function. The first group relates to genes known to be involved in cell death and cell cycle, and genes coding for cellular and oxidative stress-related molecules (Fig. 2). Large regulations were observed in pro- and anti-apoptotic genes, and functionally this complex pattern results, for instance, in increased sensitivity to CD95-mediated death (Saas et al. 1999; Falsig et al. 2004a,c).

A relatively co-ordinated pattern was also observed for cell-cycle-regulated proteins, pointing to a stop of proliferation and trophic support. For instance, the neurotrophins CNTF and NT-3 were consistently down-regulated while, for example, the cell-cycle block-associated gadd45 was strongly up-regulated (Fig. 2).

Concerning oxidative stress to the environment, the whole machinery to produce peroxinitrite, cyclooxygenases, nitric oxide synthases (NOS) and the arginine transporter essential for substrate supply (cat-2), was up-regulated. This was 


\begin{tabular}{|c|c|c|c|c|c|}
\hline Identified protein & $\begin{array}{c}\text { 24h Ratio } \\
\text { Prot. }\end{array}$ & $\begin{array}{l}\text { 24h Ratio } \\
\text { Silver. }\end{array}$ & $\begin{array}{c}\text { 4h Ratio } \\
\text { array }\end{array}$ & $\begin{array}{c}\text { 16h Ratio } \\
\text { array }\end{array}$ & Acc. Number \\
\hline IFN-induced protein with tetraco peptide repeats 3 & & $>25$ & 3.4 & 13.4 & gil 13277849 \\
\hline Thymidylate kinase family LPS-inducible (TYKi) & 21.7 & 8.3 & 14 & 13.5 & gi| 15805018 \\
\hline Purine-nucleoside phosphorylase & 2.3 & & 3.4 & 3.3 & gi|388921 \\
\hline Purine-nucleoside phosphorylase western wild mouse & & 3.3 & n.d. & n.d. & gi|2 143548 \\
\hline Proteaso me 28 subunit, alpha (PA28 $\alpha)$ & 3.1 & 9.9 & 1.6 & 1.3 & gil 1698570 \\
\hline Proteasome 28 subunit, beta (PA28 $\beta$ ) & 2.9 & & 1.8 & 4.6 & gi|20137004 \\
\hline Chloride intracellular channel 4 & 1.5 & & 6.1 & 3.7 & gi|7304963 \\
\hline Actin rel. protein $2 / 3$ complex, subunit 5 & 3.3 & & 1.7 & 1.1 & gi| 13385866 \\
\hline Beta-2-microglobulin & 10.2 & & 2.5 & 6.6 & gi|6753156 \\
\hline Interferon inducible GTPase & & 9 & 11.6 & 9.7 & gi|11140831 \\
\hline $34 / 67 \mathrm{kDa}$ Laminin receptor & & 1.5 & 1.8 & 4.3 & gi|125970 \\
\hline MnSOD & & 2.9 & 3.5 & 9.6 & gi|3041732 \\
\hline Tumor rejection antigen, GP 96 & & 1.6 & 1.3 & 1.3 & gil 14714625 \\
\hline Ornithine aminotransferase & & 1.5 & 0.7 & 0.9 & gi|8393866 \\
\hline Micro so mal cyto chrome b5 & & 4.2 & n.d. & n.d. & gi|27065687 \\
\hline Alpha enolase & & 5.8 & 0.6 & 0.5 & gil 13637776 \\
\hline Proteaso me protein p45/PSM C5 & & 9.5 & 0.9 & 1.4 & gi||11265288 \\
\hline
\end{tabular}

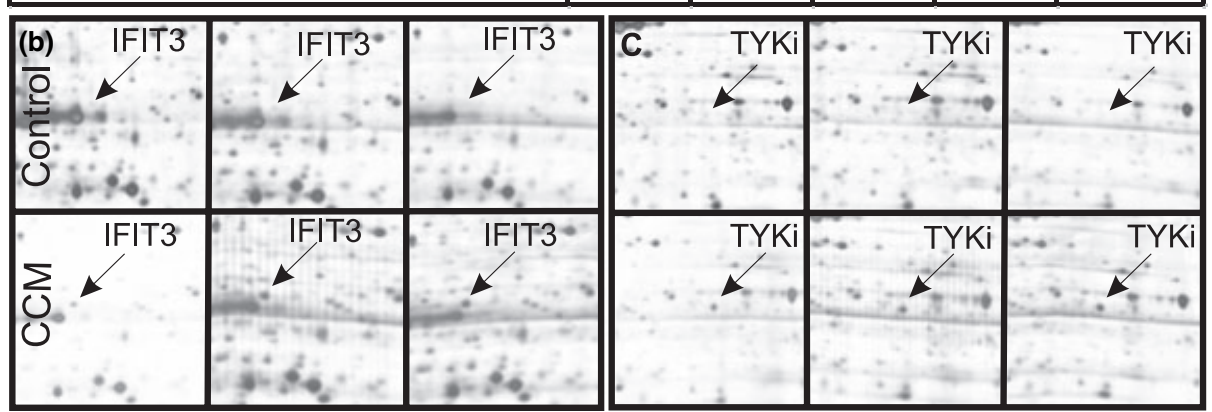

Fig. 1 Proteins with altered abundance in activated astrocytes. (a) Protein lysates from astrocytes stimulated for $24 \mathrm{~h}$ with CCM or solvent were separated on $2 \mathrm{D}$ gels and analysed for differential protein expression by an isotope ratio method (Prot.) or by silver staining (Silver). Proteins were identified by mass-spectrometry sequencing. For comparison, the regulation of the corresponding genes after 4 and $16 \mathrm{~h}$

paralleled by an increased intracellular defence via enhanced transcription of peroxiredoxin and mitochondrial superoxide dismutase (sod-2) (Fig. 2).

Many of these responses are in good agreement with previous studies on astrocyte activation using direct measures, e.g. of NOS activity or prostaglandin production. Moreover, the chip data agree well with Q-PCR data of, for example, BIRC-1/2/3, BID, CD95, cFLIP, Cox-2 and iNOS, as shown elsewhere (Falsig et al. 2004a,c). Thus, having used this group of genes successfully as a positive control for the validity of the chip data, we moved on to further analysis.

\section{Genes known to be involved in innate immunity}

The next conspicuous groups were genes involved in innate and adaptive immunity (Fig. 3). As expected, and serving as a positive control within this group, the expression of genes coding for the cytokines, IL-6 and GM-CSF were heavily enhanced. Inflammatory caspases (caspase 1 and 11) necessary for the processing and release of IL-1 and IL-18 were up-regulated together with the mRNA for IL-1 and IL-18. Conversely, IL-1 ra was down-regulated, further emphasizing the co-ordinated regulation of IL-1-related molecules. In
$\mathrm{CCM}$ stimulation is also indicated. Only proteins with $>1.4$-fold regulation with a confidence interval of $95 \%$ are shown. (b) Example of IFIT3 regulation identified on silver-stained gels. (c) Example of TYKi regulation identified on silver-stained gels. The horizontal axis represents the $\mathrm{pH}$ range from 4 to 7 . The vertical axis represents the molecular weight separation: MW (IFIT3), 48 kDa; MW (TYKi), 44.7 kDa.

addition IFN- $\beta$, Oncostatin M and IL-15 were up-regulated. All of these molecules are involved in activation of T cells, microglia and astrocytes, suggesting that astrocytes are capable of shaping and redirecting an ongoing immune response. This modulating/shaping character of the astrocyte response is corroborated by the fact that the gene regulation profile observed was not exclusively pro-inflammatory. Negative regulators of cytokine signalling were also up-regulated. Chitinase 3-like molecule and ZFP-36 are both known to antagonize IL-1 $\beta$ and TNF- $\alpha$ signalling by different mechanisms (Taylor et al. 1996; Ling and Recklies 2004). Furthermore, we observed a strong up-regulation of negative regulators of JAK/STAT signalling (SOCS1-3) (Figs 3 and 4), and a molecule linked to a switch from a Th1 to a Th2 response, Crip-1.

Apart from the general inflammatory response, we observed that many genes involved in the detection and defence against bacteria, viruses and parasites were regulated. Many of these have been described before in microglia and other experimental paradigms of macrophage activation, but the clear pattern found here upon a sterile activation of astrocytes alone was intriguing; we therefore compiled a 


\begin{tabular}{|c|c|c|c|}
\hline \multicolumn{4}{|c|}{ Cell death and stress } \\
\hline Cell death & $4 \mathrm{~h}$ & $16 \mathrm{~h}$ & \\
\hline B-cell leukemia/lymphoma 2 related prot.a1a & $1.5 \pm 0.1$ & $2.4 \pm 1.7$ & NM_009742 \\
\hline BID, Bh3 interacting domain death agonist & $6.9 \pm 4.6$ & $5.8 \pm 1.2$ & NM_007544 \\
\hline BID3, Bh3 interacting (w. bcl2 fam.) domain & $1.1 \pm 0.1$ & $3.0 \pm 1.4$ & NM_007545 \\
\hline Birc1e, Baculoviral iap repeat-containing 1e & $3.3 \pm 1.0$ & $1.1 \pm 0.2$ & NM_010870 \\
\hline Birc2, Baculoviral iap repeat-containing 2 & $12.2 \pm 2.6$ & $6.0 \pm 1.3$ & NM_007464 \\
\hline Birc3, Baculoviral iap repeat-containing 3 & $8.7 \pm 3.6$ & $3.6 \pm 2.4$ & NM_007465 \\
\hline CD95, FAS & $4.3 \pm 0.9$ & $2.1 \pm 0.7$ & NM_007987 \\
\hline cFLIP, Casp8 and fadd-like apoptosis reg. & $3.0 \pm 0.6$ & $1.8 \pm 0.4$ & NM_009805 \\
\hline Daxx, Fas death domain-associated protein & $2.1 \pm 0.7$ & $1.8 \pm 0.4$ & NM_007829 \\
\hline Endophilin B1, Bax-interacting factor 1, & $1.6 \pm 0.6$ & $2.0 \pm 0.9$ & NM_016009 \\
\hline Receptor (tnfrsf)-interact. ser-threo kinase 1 & $5.7 \pm 1.9$ & $6.9 \pm 2.5$ & NM_009068 \\
\hline \multicolumn{4}{|l|}{ Cell cycle, stress, growth factors } \\
\hline Bip, Heat shock $70 \mathrm{kd}$ prot.5 (glu-reg. Prot.) & $1.6 \pm 0.8$ & $2.4 \pm 0.9$ & BC050927 \\
\hline Cdc2a, Cell division cycle 2 homolog a & $1.1 \pm 0.3$ & $0.6 \pm 0.1$ & NM_007659 \\
\hline CHOP-10, gadd 153 & $0.9 \pm 0.1$ & $3.4 \pm 0.8$ & NM_007837 \\
\hline CNTF, Ciliary neurotrophic factor 1 & $0.4 \pm 0.1$ & $0.5 \pm 0.1$ & NM_170786 \\
\hline Cyclin a2 & $0.9 \pm 0.2$ & $0.4 \pm 0.1$ & NM_009828 \\
\hline FGFb, Fgf-2, fibroblast growth factor 2 & $0.8 \pm 0.4$ & $3.6 \pm 2.2$ & NM_008006 \\
\hline Gadd45b, Growth arrest dna-damage-ind $45 \beta$ & $7.2 \pm 1.2$ & $5.2 \pm 1.5$ & NM_008655 \\
\hline Hrsp 12, Heat-responsive protein 12 & $0.6 \pm 0.2$ & $0.5 \pm 0.1$ & NM_008287 \\
\hline IGFBP-5, Insulin-like growth factor bind. prot.5 & $1.3 \pm 0.6$ & $0.1 \pm 0.1$ & NM_0 010518 \\
\hline Neurotrophin 3 & $0.5 \pm 0.2$ & $0.5 \pm 0.2$ & NM_008742 \\
\hline Replication protein $\mathrm{A} 3$ & $0.8 \pm 0.2$ & $0.4 \pm 0.1$ & BC028489 \\
\hline Tp53bp2, Tumor prot. p53 binding protein, 2 & $0.6 \pm 0.1$ & $0.6 \pm 0.1$ & BC030894.1 \\
\hline TrkB, Neurotrophic tyr. kinase, receptor, type 2 & $0.8 \pm 0.1$ & $0.5 \pm 0.1$ & NM_008745 \\
\hline TRP73, Transformation related protein 73 & $1.6 \pm 0.3$ & $3.7 \pm 0.7$ & $\mathrm{XM} \_131858$ \\
\hline \multicolumn{4}{|l|}{ Oxidative stress } \\
\hline $\mathrm{CD} 53$ & $1.3 \pm 0.4$ & $2.1 \pm 2.0$ & NM_007651 \\
\hline Cox-1, Prostaglandin-endoperoxide synthase 1 & $1.1 \pm 0.3$ & $2.2 \pm 0.6$ & NM_008969 \\
\hline Cox-2, Prostaglandin-endoperoxide synthase 2 & $4.3 \pm 1.1$ & $2.0 \pm 0.4$ & NM_011198 \\
\hline Solute carrier fam.7 (cationic AA transp., $\mathrm{y}^{+}$), 2 & $1.3 \pm 0.3$ & $2.3 \pm 0.8$ & NM_007514 \\
\hline Metallothionein 1 & $0.5 \pm 0.2$ & $0.4 \pm 0.1$ & $\mathrm{BC} 036990$ \\
\hline Metallothionein 3 & $0.7 \pm 0.3$ & $0.3 \pm 0.1$ & NM_013603 \\
\hline nNos, Nitric oxide synthase 1 & $2.5 \pm 1.0$ & $0.8 \pm 0.3$ & NM_008712 \\
\hline iNOS, Nitric oxide synthase 2 , inducible, & $4.3 \pm 0.5$ & $2.7 \pm 0.4$ & NM_010927 \\
\hline Peroxiredoxin-1 & $1.1 \pm 0.2$ & $2.0 \pm 0.5$ & NM_011034 \\
\hline SOD2, Superoxide dismutase 2 , mitochondrial & $3.5 \pm 0.9$ & $9.7 \pm 3.6$ & NM_013671 \\
\hline
\end{tabular}

Fig. 2 Transcriptional regulation of genes related to cell death, cell cycle, oxidative stress and growth/survival factors. Cells were treated with CCM for 4 or $16 \mathrm{~h}$ before total RNA was purified and prepared for hybridization experiments. Data presented are the average values \pm index of variation (IV) from four hybridizations $(4 \mathrm{~h})$ or six hybridizations (16 h) using RNA from two or three experiments, respectively. Non-significant regulations are marked light grey. Significant up-regulations (three out of four hybridizations show a ratio $>1.9$ ) are marked dark grey. Significant down-regulations (three out of four hybridizations show a ratio $<0.6$ ) are marked white. The indicated IV (calculated as standard deviation without weighing of values) gives information on data spread, but was not utilized for significance calculations.

separate diagram of these up-regulations. Briefly, pattern recognition receptors such as TLR-1, TLR-2, TLR-4/CD14 and macrophage scavenger receptor- 1 were all up-regulated, allowing astrocytes to perform a more thorough surveillance of the extracellular environment. Furthermore, we observed a strong increase in transcripts of a family of pattern recognition molecules, the pentraxins (SAA 2, SAA 3, PTX3 and
C-reactive protein) that are involved in bacterial opsonization. These molecules are known to be able to activate the complement system through $\mathrm{C} 1 \mathrm{q}$ and indeed, $\mathrm{C} 1 \mathrm{q}$ and complement components $\mathrm{C} 3$ and $\mathrm{C} 9$ were also up-regulated. Also, two interferon-regulated GTPases and a metal-sequestering protein linked to anti-viral and anti-bacterial responses, respectively, were heavily up-regulated (GBP-2, Iigp1 and lipocalin-2) (Fig. 5).

\section{Genes known to be involved in adaptive immunity}

We were particularly intrigued about the role astrocytes may play as links between innate and adaptive immunity, and focused on two particular biological responses. First, we looked at genes related to antigen presentation and found many of these to be strongly enhanced. For instance, MHC class I and class II molecules were up-regulated together with various proteasome subunits (PA28 $\beta$, LMP2, LMP7 and MECL1). Furthermore, we found that several molecules related to $\mathrm{MHC}$ peptide loading and co-stimulation were regulated (CD81, Calreticulin, TAP1, TAP2 and CD40) (Fig. 3). These data provide evidence for the potential of astrocytes to link a sterile innate immune response to a subsequent T-cell activation in vitro (Fig. 6).

\section{Genes involved in leucocyte attraction and invasion}

As a second area of focus, we examined genes related to the invasion of $\mathrm{T}$ cells and other immune effector cells. We observed a very strong enhancement of transcription for chemokines and adhesion molecules regulating lymphocyte entry into the CNS (Fig. 7). In addition, genes were regulated which are involved in the proteolysis of the extracellular matrix (MMP3) and in regulating the opening of the BBB (uPA, TIMP1-3, PAI-1) (Fig. 8) This pattern of co-ordinated stimulation suggests that astrocytes not only stimulate peripheral immune effector cells when present within the CNS but also, affect their migration into the brain by massively producing chemotactic signals, degrading the extracellular matrix and up-regulating adhesion molecules, thus making the tissue more permissive to infiltrating cells. Furthermore, astrocytes may directly affect the permeability of the BBB by releasing proteolytic enzymes or downregulating their inhibitors (Fig. 9).

\section{Genes involved in signalling}

The last group of inflammation-related genes activated by CCM in astrocytes is that linked to various signalling pathways (Fig. 4). For most signalling pathways, the number of genes on our inflammation-specific chip was too small to yield clear functional patterns, with the exception of genes linked to the NF- $\kappa B$ family. The latter were consistently and co-ordinately up-regulated, as expected from a glial response to IL- $1 \beta$ and TNF- $\alpha$ stimulation, and as another useful positive control for the sensitivity of our chip approach. 


\begin{tabular}{|c|c|c|c|}
\hline \multicolumn{4}{|c|}{ Immunity } \\
\hline Innate imunity & $4 \mathrm{~h}$ & $16 \mathrm{~h}$ & \\
\hline Balb/c gp $49 \mathrm{~b}$ gene & $2.2 \pm 0.5$ & $2.7 \pm 0.7$ & U05265 \\
\hline C1q, Complement component १q & $10.2 \pm 2.2$ & $20.6 \pm 2.9$ & NM_007572 \\
\hline C-3, Complement component 3 & $6.1 \pm 1.9$ & $3.7 \pm 1.1$ & NM_009778 \\
\hline C-9, Complement component 9 & $1.7 \pm 0.7$ & $3.8 \pm 1.8$ & NM_013485 \\
\hline C-reactive protein & $7.7 \pm 2.5$ & $5.4 \pm 1.0$ & XM_192874 \\
\hline Caspase 1 & $1.4 \pm 0.3$ & $3.5 \pm 1.7$ & NM_009807 \\
\hline Caspase 4, caspase 11 & $3.5 \pm 2.1$ & $1.8 \pm 0.6$ & NM_007609 \\
\hline Caspase 4/ caspase 11 & $21.2 \pm 13.4$ & $22.8 \pm 20$. & NM_007609 \\
\hline CD14 & $2.4 \pm 1.0$ & $1.2 \pm 0.3$ & NM_009841 \\
\hline CD-23, Fc receptor, low affinity II, a-polypep. & $0.8 \pm 0.1$ & $0.4 \pm 0.1$ & NM_013517 \\
\hline CD40 ligand, TNF-L superfamily, member 5 & $2.4 \pm 0.0$ & $6.4 \pm 1.5$ & NM_0116 16 \\
\hline Chi3l1, Chitinase 3-like 1 & $2.0 \pm 1.0$ & $4.1 \pm 1.9$ & NM_007695 \\
\hline Crip 1, Cysteine-rich protein 1 (intestinal) crip 1 & $0.6 \pm 0.3$ & $0.6 \pm 0.2$ & NM_007763 \\
\hline GM -CSF & $11.6 \pm 4.7$ & $2.8 \pm 0.3$ & NM_009969 \\
\hline Guanylate nucleotide binding protein 2 & $42.9 \pm 13.9$ & $38.8 \pm 10.6$ & NM_010260 \\
\hline Hemolytic complement & $0.7 \pm 0.3$ & $0.2 \pm 0.1$ & NM_010406 \\
\hline Interferon-inducible GTPase, ligp1 & $11.6 \pm 2.6$ & $11.3 \pm 6.4$ & NM_021792 \\
\hline IFN-ind.prot. w. tetratricopeptide rep. 1, IFIT1 & $9.1 \pm 3.3$ & $14.7 \pm 6.6$ & NM_008331 \\
\hline IFN-ind.prot. w. tetratricopeptide rep.3, IFIT3 & $3.4 \pm 0.8$ & $12.6 \pm 4.4$ & NM_010501 \\
\hline IFNb, Interferon beta & $6.1 \pm 0.9$ & $1.6 \pm 0.5$ & NM_0 010510 \\
\hline Immunoresponsive gene 1, IRG-1 & $19.1 \pm 4.9$ & $10.7 \pm 6.4$ & XM_127883 \\
\hline Interleukin 1 beta & $0.6 \pm 0.2$ & $2.0 \pm 1.3$ & NM_008361 \\
\hline Interleukin 1 receptor antagonist & $0.9 \pm 0.1$ & $0.6 \pm 0.1$ & NM_031167 \\
\hline Interleukin 6 & $27.9 \pm 5.5$ & $9.8 \pm 6.6$ & NM_031168 \\
\hline Interleukin 12 receptor, beta 2 & $19.0 \pm 4.7$ & $13.4 \pm 7.5$ & NM_008354 \\
\hline Interleukin 15 & $7.7 \pm 1.3$ & $4.7 \pm 0.9$ & NM_008357 \\
\hline Interleukin 18 & $0.9 \pm 0.5$ & $2.9 \pm 0.8$ & NM_008360 \\
\hline Lipocalin 2 & $9.5 \pm 2.3$ & $15.3 \pm 10.5$ & XM_130171 \\
\hline M acrophage scavenger receptor 1 & $2.1 \pm 0.6$ & $3.9 \pm 1.9$ & NM_031195 \\
\hline Nup475, Zfp-36, Zinc finger protein 36 & $4.9 \pm 1.0$ & $2.5 \pm 0.7$ & NM_0 011756 \\
\hline Oncostatin M & $2.1 \pm 0.5$ & $2.7 \pm 0.3$ & AK087945 \\
\hline Oncostatin M receptor & $6.5 \pm 1.3$ & $4.1 \pm 1.9$ & NM_0 011019 \\
\hline Prostaglandin e receptor 3 (subtype ep 3 ) & $0.2 \pm 0.1$ & $0.2 \pm 0.1$ & NM_011196 \\
\hline PTX3, pentaxin related gene & $40.1 \pm 8.2$ & $37.9 \pm 16.0$ & $\times 83601$ \\
\hline Serum amyloid a 2 & $8.2 \pm 2.4$ & $9.4 \pm 4.1$ & NM_0 011314 \\
\hline Serum amyloid a 3 & $4.5 \pm 1.2$ & $7.7 \pm 4.0$ & NM_011315 \\
\hline Toll-like receptor 1 & $1.0 \pm 0.3$ & $2.4 \pm 0.6$ & NM_030682 \\
\hline Toll-like receptor 2 & $63.8 \pm 27.3$ & $39.6 \pm 15.1$ & BC0 14693 \\
\hline Toll-like receptor 4 & $2.1 \pm 0.7$ & $1.9 \pm 0.6$ & NM_02 1297 \\
\hline Trim30, Tripartite motif protein 30 & $1.9 \pm 0.3$ & $4.5 \pm 2.2$ & NM_009099 \\
\hline \multicolumn{4}{|l|}{ Adaptive imm unity } \\
\hline beta-2-microglobulin. & $2.5 \pm 0.7$ & $6.9 \pm 2.3$ & NM_009735 \\
\hline Calreticulin & $1.1 \pm 0.4$ & $2.0 \pm 0.7$ & NM_007591 \\
\hline Cathepsin L & $1.1 \pm 0.3$ & $0.5 \pm 0.2$ & NM_009984 \\
\hline CD40, TNF receptor superfamily, member 5 & $8.3 \pm 5.3$ & $3.8 \pm 1.0$ & NM_011611 \\
\hline CD81 & $1.4 \pm 0.8$ & $2.1 \pm 1.3$ & NM_133655 \\
\hline $\mathrm{H}-2$ I q gene for class $1 \mathrm{M} \mathrm{HC}$ glycoprotein & $1.2 \pm 0.2$ & $5.0 \pm 1.7$ & $\mathrm{X} 14091$ \\
\hline H2-D, Histocompatibility 2, d region locus 1 & $3.3 \pm 1.1$ & $7.1 \pm 2.4$ & NM_010380 \\
\hline Histocompatibility 2, class II, locus mb2 & $1.1 \pm 0.5$ & $3.8 \pm 1.7$ & NM_010388 \\
\hline Lmp2, Proteosome subunit, beta type 9 & $4.4 \pm 1.2$ & $7.0 \pm 1.7$ & NM_013585 \\
\hline Lmp7, Proteosome subunit, beta type 8 & $3.8 \pm 1.0$ & $7.7 \pm 2.8$ & XM_289858 \\
\hline Mecl1, Proteasome subunit, beta type 10 & $1.1 \pm 0.3$ & $2.6 \pm 0.6$ & NM_0 13640 \\
\hline Proteasome subunit 28 , beta & $1.8 \pm 0.5$ & $4.5 \pm 0.6$ & XM_138688 \\
\hline Transp.1, atp-bind. cassette, sub-fam. b tap 1 & $2.1 \pm 0.5$ & $2.4 \pm 0.4$ & NM_013683 \\
\hline Transp.2, atp-bind. cassette, sub- & & & NM_011530 \\
\hline
\end{tabular}

\section{Confirmation of regulations and modulation of signal transduction}

All cell cultures used for RNA analysis were controlled for their correct functional response by measurement of $\mathrm{NO}$ production. In addition, we included some further control experiments to examine the regulation of chemokines, which
Fig. 3 Transcriptional regulation of genes related to innate and adaptive immunity. Cells were treated with CCM for 4 or $16 \mathrm{~h}$ before total RNA was purified and prepared for hybridization experiments. Data presented are the average values \pm index of variation (IV) from four hybridizations $(4 \mathrm{~h})$ or six hybridizations (16 h) using RNA from two or three experiments, respectively. Non-significant regulations are marked light grey. Significant up-regulations (three out of four hybridizations show a ratio $>1.9$ ) are marked dark grey. Significant down-regulations (three out of four hybridizations show a ratio $<0.6$ ) are marked white. The indicated IV (calculated as standard deviation without weighing of values) gives information on data spread, but was not utilized for significance calculations.

seemed to be extensively induced according to the chip analysis. The regulation of MCP-1 and RANTES (Figs 10a and b) was confirmed by RT-PCR. Moreover, release of RANTES was also detected at the protein level by ELISA measurements, showing that astrocytes are capable of a very high production of chemokines after CCM stimulation (Fig. 10d).

We also controlled for the induction of TLR-4, IL-18 (not shown), PAI-1 (Fig. 10c), and TYKi and IFIT-3 (Fig. 10e). All regulations detected by the chip, analysed by PCR, were confirmed. For the latter two genes, we also investigated whether induction of these RNAs paralleled the extent of the inflammatory response. For this purpose, the transcriptional response was measured in cells pre-treated with agents known to affect the inflammatory process in astrocytes. We used isoprenaline (beta-adrenergic receptor agonist), forskolin plus rolipram (phosphodiesterase-4 inhibitor), two treatment regimens resulting in elevated levels of the intracellular second messenger cAMP. Futhermore, we investigated the role of the MAP-kinase pathways by using the $\mathrm{p} 38$ inhibitor SB203580 or the mixed lineage kinase inhibitor CEP1347. CEP1347 is an upstream inhibitor of the JNK pathway. All agents have previously been shown to down-regulate cytokine production from astrocytes and here, we found that all compounds reduced the up-regulation of TYKi and IFIT3 mRNA significantly (Fig. 10f).

\section{Discussion}

In this study, we analysed the profile of cytokine-stimulated murine astrocytes (an in vitro model attempting to simulate a strong inflammatory situation in the CNS) by quantitative differential proteomics analysis and by competitive oligonucleotide hybridization analysis. We then compared our data with those from previous studies using conventional and arrayed approaches on murine and human astrocytes and macrophages (Eddleston AND Mucke 1993; Baker and Manuelidis 2003; Ambrosini and Aloisi 2004; John et al. 2005). With respect to regulation of the inflammation-linked molecules, we see a good correlation with the data from a human adult astrocyte chip study (Meeuwsen et al. 2003), despite species differences (man vs. mouse) and the use of 


\begin{tabular}{|c|c|c|c|}
\hline \multicolumn{4}{|c|}{ Signalling } \\
\hline Signalling & $4 \mathrm{~h}$ & $16 \mathrm{~h}$ & \\
\hline Activating transcription factor 3 & $2.5 \pm 1.2$ & $1.3 \pm 0.4$ & NM_007498 \\
\hline Activating transcription factor 4 & $2.1 \pm 0.7$ & $3.1 \pm 0.8$ & NM_009716 \\
\hline Angiotensin receptor-like 1 & $2.5 \pm 1.0$ & $1.8 \pm 0.9$ & NM_011784 \\
\hline Apolipoprotein E & $0.6 \pm 0.3$ & $0.5 \pm 0.1$ & NM_009696 \\
\hline Benzodiazepine receptor, peripheral & $1.0 \pm 0.3$ & $3.9 \pm 0.8$ & BC002055 \\
\hline Ccaat/enhancer binding protein (c/ebp), delta & $2.5 \pm 1.6$ & $2.5 \pm 0.8$ & NM_007679 \\
\hline CD72 antigen & $13.5 \pm 2.6$ & $12.2 \pm 6.4$ & NM_007654 \\
\hline c-Jun & $2.5 \pm 0.4$ & $1.6 \pm 0.3$ & BC032086 \\
\hline DISP1, Dispatched homolog 1(drosophila) & $1.6 \pm 0.7$ & $2.5 \pm 1.2$ & NM_026866 \\
\hline Dual specificity phosphatase 1 & $0.7 \pm 0.2$ & $0.2 \pm 0.1$ & NM_0 13642 \\
\hline Early growth response 1 & $1.1 \pm 0.2$ & $2.1 \pm 0.5$ & NM_007913 \\
\hline Galectin- 3 , galactose binding, soluble 3 & $1.8 \pm 0.2$ & $2.0 \pm 1.0$ & XM_127681 \\
\hline GPR37, PAELR, G protein-coupled receptor 37 & $1.7 \pm 1.3$ & $2.1 \pm 1.9$ & NM_005302 \\
\hline GSK3-alpha, Glycogen synthase kinase-3 alpha & $2.2 \pm 0.6$ & $1.7 \pm 0.4$ & XM_133269 \\
\hline Homer1, Homer homolog 1 (drosophila) & $1.1 \pm 0.1$ & $2.4 \pm 3.2$ & NM_147176 \\
\hline Immediate early response 3 & $7.5 \pm 2.4$ & $4.4 \pm 1.7$ & NM_133662 \\
\hline Interferon regulatory factor 1 & $10.2 \pm 5.9$ & $6.3 \pm 1.5$ & NM_008390 \\
\hline Interferon regulatory factor 8 & $4.5 \pm 0.7$ & $2.5 \pm 0.6$ & NM_008320 \\
\hline Nurr1, Nuc. receptor subfam. 4, group a, memb. 2 & $0.6 \pm 0.3$ & $0.4 \pm 0.1$ & NM_013613 \\
\hline PAR-4, Pawr, Prkc, apoptosis, wt 1, regulator & $0.6 \pm 0.2$ & $0.7 \pm 0.3$ & XM_125814 \\
\hline Pleckstrin hom.like domain, family a, member 1 & $3.7 \pm 0.4$ & $4.1 \pm 0.7$ & NM_009344 \\
\hline Regulator of g-protein signaling 2 & $0.3 \pm 0.1$ & $0.3 \pm 0.1$ & NM_009061 \\
\hline Signal transducer and activator of transcription 6 & $2.1 \pm 0.2$ & $2.6 \pm 1.1$ & NM_009284 \\
\hline $\mathrm{db} /$ cortin and $\mathrm{Ca} / \mathrm{calm}$-dep. prot.kinase-like 1 & $0.6 \pm 0.2$ & $0.6 \pm 0.1$ & BC050903 \\
\hline Sonic hedgehog & $2.3 \pm 0.4$ & $2.8 \pm 0.3$ & NM_009170 \\
\hline Suppressor of cytokine signaling 1 & $2.4 \pm 0.9$ & $1.8 \pm 0.5$ & NM_009896 \\
\hline Suppressor of cytokine signaling 2 & $2.0 \pm 0.2$ & $1.2 \pm 0.4$ & NM_007706 \\
\hline Suppressor of cytokine signaling 3 & $3.6 \pm 1.5$ & $2.0 \pm 0.6$ & BC052031 \\
\hline TALE family homeobox, Tg interacting factor & $2.9 \pm 0.8$ & $2.4 \pm 0.5$ & XM_192829 \\
\hline \multicolumn{4}{|l|}{ NF-kB s ignaling } \\
\hline B-cell leukemia/lymphoma 3 & $3.8 \pm 0.9$ & $3.5 \pm 0.8$ & NM_033601 \\
\hline IKB alpha & $13.9 \pm 5.8$ & $8.5 \pm 2.5$ & NM_010907 \\
\hline IkB beta & $2.0 \pm 0.5$ & $2.2 \pm 0.4$ & NM_010908 \\
\hline IKB epsilon & $3.7 \pm 1.0$ & $4.3 \pm 1.6$ & AK008843 \\
\hline $\mathrm{p} 49 / \mathrm{p} 100, \mathrm{NFkB} 2$ & $3.5 \pm 1.0$ & $2.7 \pm 0.4$ & NM_019408 \\
\hline p50/p 105, NFkB1 & $7.2 \pm 1.2$ & $3.3 \pm 0.8$ & NM_008689 \\
\hline p65 NFkB, Rela & $2.8 \pm 1.0$ & $1.8 \pm 0.6$ & NM_009045 \\
\hline RelB & $5.6 \pm 2.1$ & $4.1 \pm 0.8$ & NM_009046 \\
\hline Tnf receptor-associated factor 2 & $1.5 \pm 0.3$ & $2.3 \pm 0.4$ & NM_009422 \\
\hline
\end{tabular}

Fig. 4 Transcriptional regulation of genes related to signalling. Cells were treated with CCM for 4 or $16 \mathrm{~h}$ before total RNA was purified and prepared for hybridization experiments. Data presented are the average values \pm index of variation (IV) from four hybridizations $(4 \mathrm{~h})$ or six hybridizations (16 h) using RNA from two or three experiments, respectively. Non-significant regulations are marked light grey. Significant up-regulations (three out of four hybridizations show a ratio $>1.9$ ) are marked dark grey. Significant down-regulations (three out of four hybridizations show a ratio $<0.6$ ) are marked white. The indicated IV (calculated as standard deviation without weighing of values) gives information on data spread, but was not utilized for significance calculations.

different types of arrays (high-density, short oligonucleotide and cDNA arrays vs. low-density, long oligonucleotide arrays). Our data also corroborate the human astrocyte data of John et al. (2002), both with respect to regulation of specific genes but also regarding the types of genes and the up- or down-regulation profiles. One interesting molecule found to be up-regulated in all three studies was IL-15, a

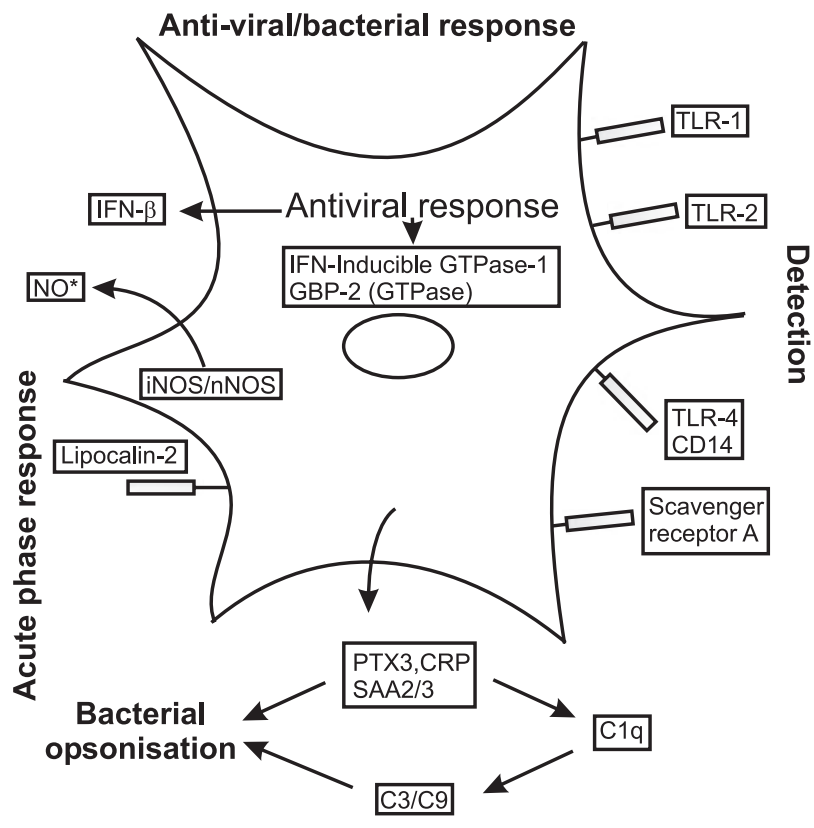

Fig. 5 Co-ordinated activation of genes related to defence against viruses and bacteria. The list of all regulated genes in activated astrocytes was scanned for those related to defence against microbial intruders. This information was then used to construct a hypothetical diagram showing where astrocytes may be altered functionally. Protein names in boxes indicate proteins/functions corresponding to genes that were found to be up-regulated at least at one time point by treatment with $\mathrm{CCM}$.

T cell activating factor shown to act as a survival/immunomodulatory factor for microglia (Hanisch et al. 1997). Our data also confirm the suggested (John et al. 2002) up-regulation of CD40, which otherwise is preferentially expressed by cells of the myeloid lineage.

The present study adds some new findings for murine astrocytes, such as the clear up-regulations of the immune responsive genes ifit1, ifit3 (irg-2), irg-1, the interferoninducible GTPases iigp 1 and $g b p-2$, and the lipopolysaccharide (LPS) inducible thymidylate kinase tyki, all previously identified in lipopolysaccharide (LPS)- or interferon-stimulated macrophages. We take this as evidence that astrocytes may express a macrophage-like gene profile when they become highly activated. This is further corroborated by comparison of our data with those obtained from murine microglia stimulated with TNF plus IFN- $\gamma$ (Paglinawan et al. 2003). All the above-mentioned genes were induced in microglia and the similarity between stimulated astrocytes and microglia is supported by the fact that out of 125 genes triggered in microglia, 42 were also found in our astrocyte study to be regulated.

In accordance with this role of astrocytes in the innate immune response, many genes known from macrophage anti-viral or anti-bacterial responses were up-regulated. One group includes factors involved in the detection of pathogens, such as pattern-recognition receptors. A second 


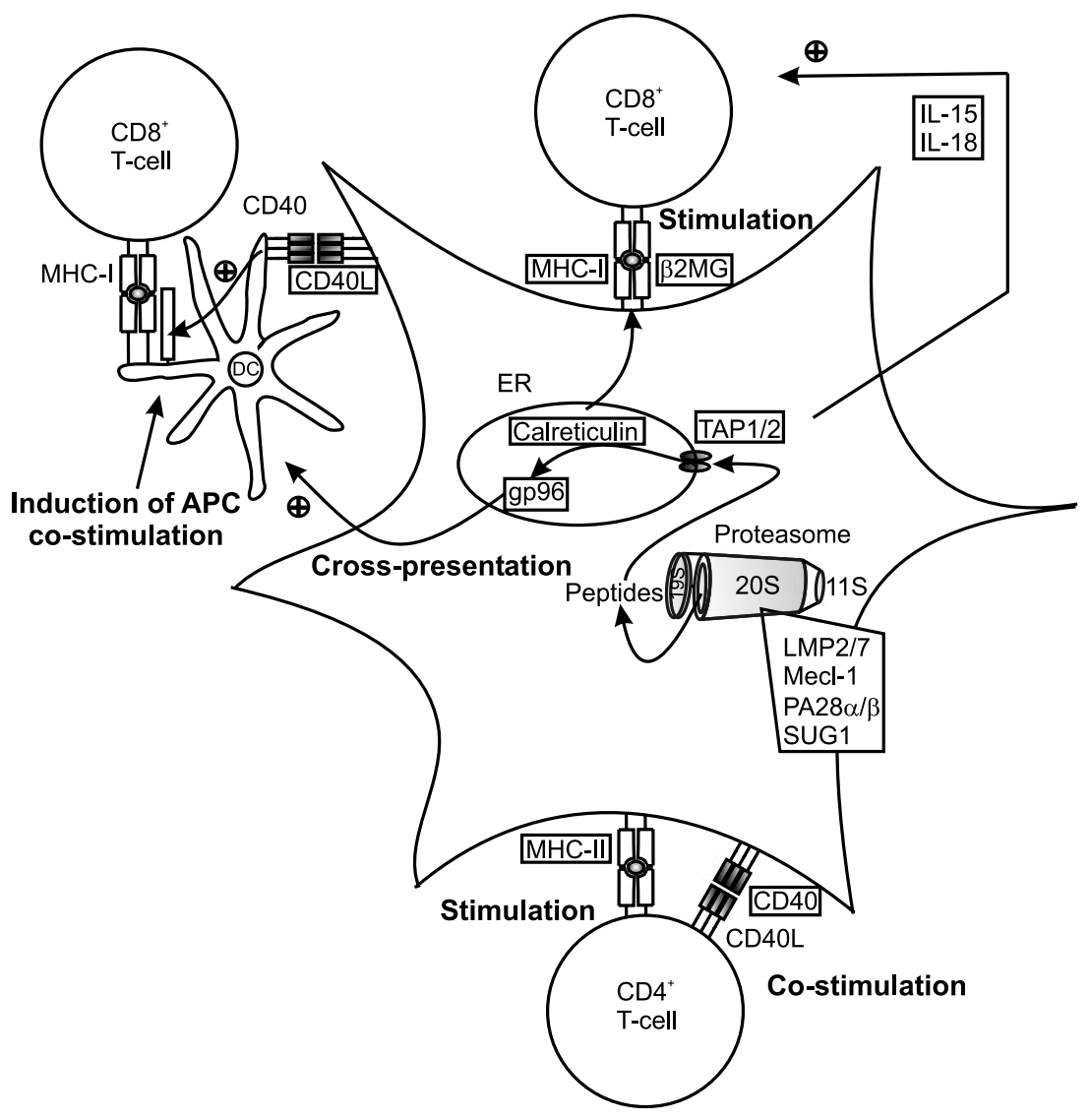

Fig. 6 Co-ordinated activation of genes related to antigen presentation. The list of all regulated genes in activated astrocytes was scanned for those related to antigen presentation. This information was then used to construct a hypothetical diagram showing where astrocytes may be altered functionally. Protein names in boxes indicate proteins/functions corresponding to genes that were found to be unregulated at least at one time point by treatment with $\mathrm{CCM}$. The central cell represents an astrocyte and potential functional implications are addressed in the discussion. group comprises diverse molecules involved in cell-cell signalling such as cytokines, chemokines and growth factors. Thirdly, we found molecules involved in an opsonizing acute-phase response such as pentraxins and complement components. Finally, we also found molecules such as iNOS, Cat-2 (the arginine carrier important for iNOS function), lipocalin-2 (an iron-sequestering molecule that limits bacterial growth) and IFN-inducible GTPases involved in a host response against intracellular pathogens (Flo et al. 2004; MacMicking 2004).

In this context, it should be noted that we have examined our cultures extensively for the presence of microglia cells, and that our culturing technique was adapted to avoid cellular contamination. We found that performing a Percoll gradient and seeding the purified cells thinly on uncoated plastic prevents the presence of microglia. We have not been able to detect the presence of microglia in our cultures using immunofluorescence staining procedures for Isolectin-B4 from Griffonia simplicifolia, or by functional assays (Falsig et al. 2004a). Further evidence for a lack of microglia is the protein landscape that shows a clear astrocytic profile (Fig. 1S) and the fact that we have performed parallel microarray studies on activated microglia with an overlapping, but also distinctive profile (unpublished data). For instance, one noticeable difference is the regulation of
MIP-1 $\alpha$. In contrast to data from human astrocytes, we found no evidence that MIP-1 $\alpha$ (CCL3) is regulated in murine astrocytes, and confirmation by Q-PCR showed almost undetectable levels of mRNA (data not shown). Murine microglia regulated both MIP-1 $\alpha$ and MIP-1 $\beta$ (CCL4) strongly upon immune stimulation by LPS (own data, not shown) while microglia stimulated by TNF plus IGN- $\gamma$ seemed to regulate neither CCL4 nor CCL3 significantly (Paglinawan et al. 2003). On this basis, it may be worth examining whether the MIP-1 induction pattern can be used as fingerprint for the type of inflammatory reaction.

Our expression analysis strongly supports the view that astrocytes are versatile cells that can take over a variety of immune functions when they are cytokine-activated. For instance, they have been shown to present antigens in vitro (Fontana et al. 1984; Neumann et al. 2002). However, astrocytes appear to be less effective compared with microglia in activating naïve $\mathrm{CD}^{+} \mathrm{T}$ cells via MHC II, probably due to lack of co-stimulatory molecules on astrocytes (Aloisi 2001). Here, we found that activated astrocytes do indeed up-regulate most of the molecules associated with MHC class I and MHC class II presentation when activated by pro-inflammatory cytokines (see Figs 3 and 7). However, it has to be cautioned that there is only little evidence on the role of astrocytes as antigen-presenting cells 


\begin{tabular}{|c|c|c|c|}
\hline \multicolumn{4}{|c|}{ CNS infiltration/Chemokines } \\
\hline C-C chemokines & $4 \mathrm{~h}$ & $16 \mathrm{~h}$ & \\
\hline MCP-1, CCL2 & $17.9 \pm 10.9$ & $10.2 \pm 4.0$ & NM_011333 \\
\hline M IP-1 beta, CCL 4 & $8.4 \pm 1.9$ & $2.1 \pm 0.9$ & NM_013652 \\
\hline RANTES, CCL 5 & $28.9 \pm 21.9$ & $9.3 \pm 6.1$ & NM_013653 \\
\hline $\mathrm{MCP}-3, \mathrm{CCL} 7$ & $34.1 \pm 8.3$ & $33.9 \pm 11.0$ & NM_013654 \\
\hline MCP-5, CCL 12 & $2.1 \pm 0.6$ & $1.7 \pm 0.3$ & NM_011331 \\
\hline MCP-5, CCL 12 & $2.2 \pm 0.7$ & $3.1 \pm 1.0$ & BC027520 \\
\hline $\mathrm{MCP}-5, \mathrm{CCL} 12$ & $7.8 \pm 2.5$ & $9.0 \pm 4.2$ & U50712 \\
\hline M IP-3 beta, CCL 19 & $1.2 \pm 0.3$ & $3.0 \pm 1.4$ & NM_011888 \\
\hline M IP-3 alpha, CCL20 & $9.7 \pm 2.2$ & $2.7 \pm 1.2$ & NM_016960 \\
\hline $\mathrm{MEC}, \mathrm{CCL} 28$ & $0.6 \pm 0.1$ & $0.6 \pm 0.2$ & XM_288015 \\
\hline \multicolumn{4}{|l|}{ C-X-C chem okines } \\
\hline GRO1, CXCL 1 & $60.4 \pm 32.4$ & $35.6 \pm 11.2$ & NM_008176 \\
\hline M IP-2 alpha, CXCL 2 & $64.8 \pm 49.4$ & $25.5 \pm 9.7$ & NM_009140 \\
\hline Mig, CXCL 9 & $40.5 \pm 24.7$ & $20.6 \pm 6.3$ & XM_289786 \\
\hline $\mathrm{IP9}, \mathrm{CXCL} 11$ & $16.9 \pm 10.8$ & $11.9 \pm 4.8$ & NM_019494 \\
\hline SDF-1alpha, CXCL 12 & $1.1 \pm 0.2$ & $3.6 \pm 1.4$ & NM_013655 \\
\hline \multicolumn{4}{|l|}{ C-X3-C family } \\
\hline CKLF5, chemokine-like factor & $0.9 \pm 0.2$ & $0.3 \pm 0.2$ & NM_026066 \\
\hline \multicolumn{4}{|l|}{ C-CR fam ily } \\
\hline M IP-1 alphaR, CCR 2 & $2.5 \pm 0.4$ & $2.0 \pm 0.9$ & BC011092 \\
\hline \multicolumn{4}{|l|}{ C-X-CR fam ily } \\
\hline ||8Rb, interleukin-8 receptor beta & $2.2 \pm 0.3$ & $1.5 \pm 0.4$ & NM_009909 \\
\hline \multicolumn{4}{|l|}{ C-X3-CR fam ily } \\
\hline Rdc1, Chemokine orphan receptor 1 & $77.9 \pm 4.6$ & $13.0 \pm 4.7$ & NM_007722 \\
\hline \multicolumn{4}{|l|}{ Adhesion } \\
\hline Cadherin-2 & $0.9 \pm 0.3$ & $0.5 \pm 0.2$ & NM_007664 \\
\hline Catenin alpha 1 & $0.9 \pm 0.2$ & $0.5 \pm 0.2$ & NM_009818 \\
\hline CD44 & $4.8 \pm 1.9$ & $10.1 \pm 2.7$ & XM_283773 \\
\hline Icam1, Intercellular adhesion molecule 1 & $10.1 \pm 1.0$ & $4.7 \pm 1.3$ & NM_010493 \\
\hline CD62E, E-selectin & $3.5 \pm 0.9$ & $1.0 \pm 0.1$ & NM_011345 \\
\hline CD62P, P-selectin & $2.4 \pm 0.6$ & $0.9 \pm 0.3$ & NM_011347 \\
\hline CD83 antigen & $3.7 \pm 1.0$ & $1.0 \pm 0.2$ & NM_009856 \\
\hline Cyr61, Cysteine rich protein 61 & $0.5 \pm 0.2$ & $0.6 \pm 0.1$ & NM 010516 \\
\hline Integrin beta 5 & $0.8 \pm 0.3$ & $0.6 \pm 0.2$ & NM 010580 \\
\hline $34 / 67 \mathrm{kda}$ laminin receptor & $1.8 \pm 0.4$ & $3.7 \pm 1.0$ & XM 285321 \\
\hline Vcam1, Vascular cell adhesion molecule 1 & $21.5 \pm 6.4$ & $19.9 \pm 6.8$ & BC029823 \\
\hline
\end{tabular}

Fig. 7 Transcriptional regulation of genes related to CNS infiltration. Cells were treated with CCM for 4 or $16 \mathrm{~h}$ before total RNA was purified and prepared for hybridization experiments. Data presented are the average values \pm index of variation (IV) from four hybridizations $(4 \mathrm{~h})$ or six hybridizations (16 h) using RNA from two or three experiments, respectively. Non-significant regulations are marked light grey. Significant up-regulations (three out of four hybridizations show a ratio $>1.9$ ) are marked dark grey. Significant down-regulations (three out of four hybridizations show a ratio $<0.6$ ) are marked white. The indicated IV (calculated as standard deviation without weighing of values) gives information on data spread, but was not utilized for significance calculations.

in vivo. In line with this, we also confirmed the lack of regulation of the co-stimulatory molecules CD80 (B7.1) and CD86 (B7.2), as earlier described by Aloisi (2001). Obviously, astrocytes express the whole machinery for presenting antigen to activated T cells, while the lack of CD80/86 may preclude priming of naïve cells. It has been postulated that astrocytes may be involved in maintaining the immune privilege of the brain by inducing anergy in $\mathrm{T}$ cells because

\begin{tabular}{|c|c|c|c|}
\hline \multicolumn{4}{|c|}{ Cellular machinery } \\
\hline Metabolism & $4 \mathrm{~h}$ & $16 \mathrm{~h}$ & \\
\hline alpha-Enolase & $0.6 \pm 0.3$ & $0.5 \pm 0.1$ & BC024644 \\
\hline Armadillo repeat gene & $0.2 \pm 0.1$ & $0.2 \pm 0.0$ & AC0 12399 \\
\hline Chloride intracellular channel 4 (mitochondrial) & $6.1 \pm 3.2$ & $3.4 \pm 1.1$ & NM_013885 \\
\hline Cytochrome b-5 & $0.7 \pm 0.1$ & $0.6 \pm 0.1$ & NM_025797 \\
\hline Cytochrome p 450 , fam. 2 , subfamily c 29 & $11.6 \pm 13.2$ & $11.9 \pm 2.5$ & NM_007815 \\
\hline Glutamine Synthase, Glutamate-ammonia ligase & $0.4 \pm 0.2$ & $0.2 \pm 0.1$ & NM_008131 \\
\hline GLT1, EAAT2, Solute carrier fam.1, member 2 & $0.9 \pm 0.2$ & $0.5 \pm 0.1$ & NM_011393 \\
\hline LDH1a, Lactate dehydrogenase 1, a chain & $1.0 \pm 0.7$ & $0.6 \pm 0.2$ & NM_010699 \\
\hline 14-3-3, phospholipase A2, group IIA & $14.5 \pm 5.6$ & $3.8 \pm 1.2$ & NM_011108 \\
\hline P2X7-receptor & $0.6 \pm 0.2$ & $0.6 \pm 0.1$ & NM_011027 \\
\hline Purine-nucleoside phosphorylase & $3.4 \pm 1.0$ & $3.2 \pm 0.5$ & NM_013632 \\
\hline Thymidylate kinase family Ips-inducible member & $14.0 \pm 4.6$ & $12.8 \pm 5.5$ & NM_020557 \\
\hline Vesicular monoamine transporter 2 & $3.0 \pm 0.6$ & $2.9 \pm 0.7$ & NM_172523 \\
\hline \multicolumn{4}{|l|}{ Proteolys is } \\
\hline Annexin a2 & $1.4 \pm 0.3$ & $0.5 \pm 0.0$ & BC005763 \\
\hline APP, Amyloid beta (a4) precursor protein & $0.7 \pm 0.1$ & $0.5 \pm 0.1$ & NM_007471 \\
\hline Beta-site app cleaving enzyme, BACE-1 & $1.1 \pm 0.1$ & $3.3 \pm 1.5$ & BC048189 \\
\hline Cathepsin C preproprotein, & $2.2 \pm 0.3$ & $1.9 \pm 0.4$ & U89269 \\
\hline CD 141, Thrombomodulin & $4.4 \pm 1.7$ & $6.4 \pm 6.0$ & NM_009378 \\
\hline CD 142, Coagulation factor III, Tissue factor & $2.0 \pm 0.6$ & $1.2 \pm 0.4$ & BC0 16397 \\
\hline Endothelin 1 & $0.6 \pm 0.2$ & $0.4 \pm 0.1$ & NM_010104 \\
\hline M atrix metalloproteinase 3 & $12.7 \pm 4.8$ & $15.8 \pm 3.8$ & NM_010809 \\
\hline parkin 2, PD (autosom. reces., juv.) 2, isoform3 & $0.8 \pm 0.2$ & $0.6 \pm 0.2$ & NM_013988 \\
\hline Plasminogen activator inhibitor-1 & $8.0 \pm 3.6$ & $6.0 \pm 2.8$ & NM_008871 \\
\hline Tissue inhibitor of metalloproteinase 1 & $3.0 \pm 1.6$ & $4.4 \pm 2.0$ & NM_011593 \\
\hline Tissue inhibitor of metalloproteinase 2. & $0.7 \pm 0.1$ & $0.5 \pm 0.1$ & $\times 62622$ \\
\hline Tissue inhibitor of metalloproteinase 3 & $0.6 \pm 0.1$ & $0.5 \pm 0.2$ & NM_011595 \\
\hline $\mathrm{u}-\mathrm{Pa}$, Plasminogen activator, urokinase & $3.4 \pm 0.8$ & $2.7 \pm 0.4$ & NM_008873 \\
\hline \multicolumn{4}{|l|}{ others } \\
\hline GFAP, Glial fibrillary acidic protein & $0.8 \pm 0.1$ & $0.6 \pm 0.2$ & AF332062 \\
\hline Riken cdna b $130024 \mathrm{~b} 19$ gene, tumor antigene? & $2.4 \pm 0.6$ & $1.6 \pm 0.5$ & NM_172508 \\
\hline Tubulin, alpha 1 & $0.8 \pm 0.3$ & $0.5 \pm 0.2$ & NM_011653 \\
\hline
\end{tabular}

Fig. 8 Transcriptional regulation of genes related to metabolism and proteolysis. Cells were treated with CCM for 4 or $16 \mathrm{~h}$ before total RNA was purified and prepared for hybridization experiments. Data presented are the average values \pm index of variation (IV) from four hybridizations ( $4 \mathrm{~h}$ ) or six hybridizations (16 h) using RNA from two or three experiments, respectively. Non-significant regulations are marked light grey. Significant up-regulations (three out of four hybridizations show a ratio $>1.9$ ) are marked dark grey. Significant down-regulations (three out of four hybridizations show a ratio <0.6) are marked white. The indicated IV (calculated as standard deviation without weighing of values) gives information on data spread, but was not utilized for significance calculations.

they present antigens without co-stimulatory antigens. This phenomenon may apply mainly to the basic non-inflammatory condition and to experiments with cell lines because long-term unresponsiveness is not induced in primary $\mathrm{T}$ cells by lack of co-stimulatory molecules (Abbas and Sharpe 2005). We found that CD40-L was up-regulated on activated astrocytes. CD40-L is known to induce co-stimulatory molecules such as CD80 and CD86 on dendritic cells, and the production of IL-12 in macrophages. In addition, gp96, an endoplasmic reticulum (ER) chaperone that binds $\mathrm{MHC}$ class I peptides, was up-regulated in astrocytes on the protein level. Gp96 (and calreticulin) with their bound peptides can, 


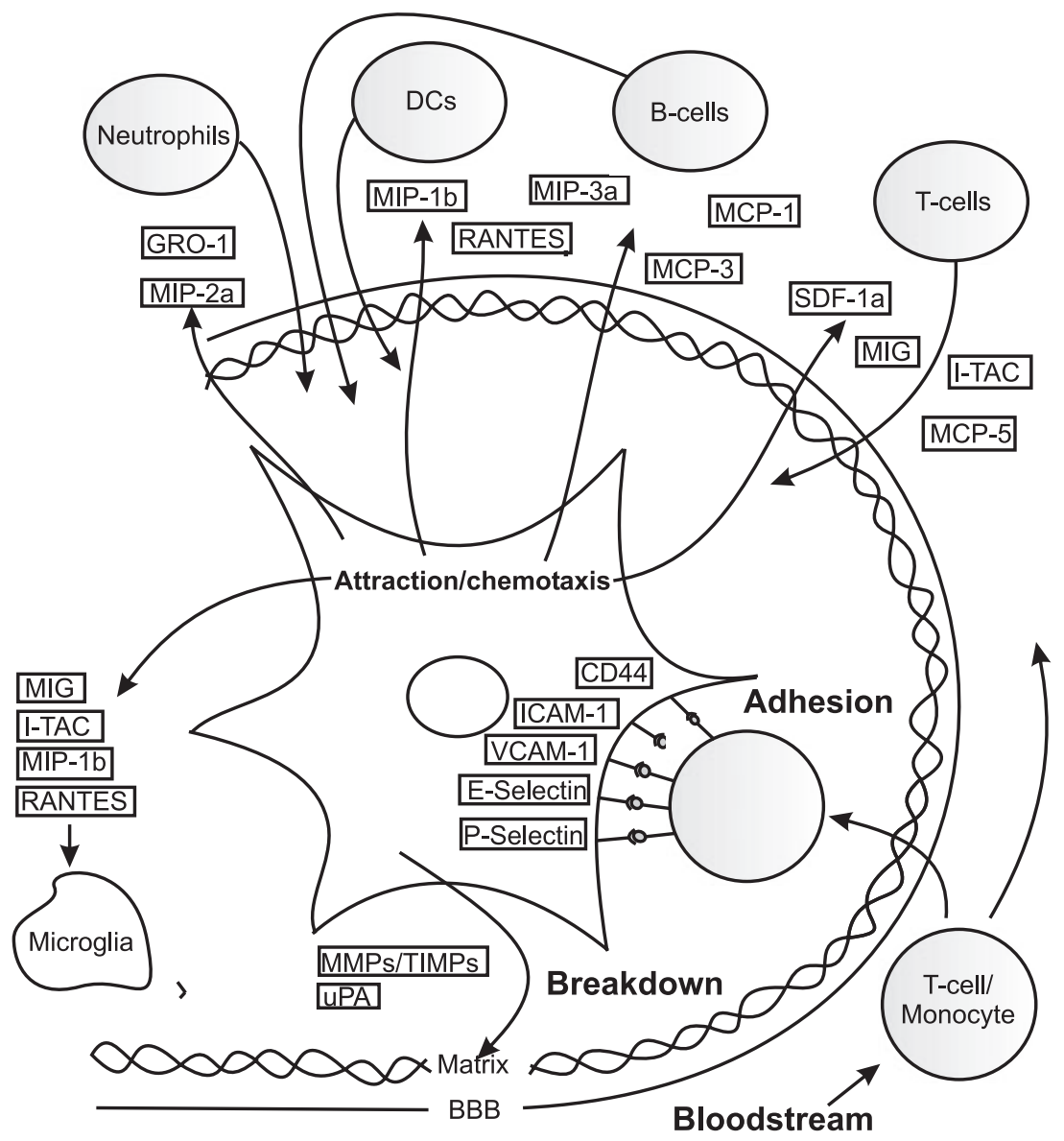

Fig. 9 Co-ordinated activation of genes related to leucocyte attraction. The list of all regulated genes in activated astrocytes was scanned for those related to leucocyte attraction. This information was then used to construct a hypothetical diagram showing where astrocytes (central cell in diagram) or other cells and structures may be altered functionally due to astrocyte gene regulation. Protein names in boxes indicate proteins/functions corresponding to genes that were found to be regulated at least at one time point by treatment with CCM. if excreted after cell damage, be taken up by professional antigen-presenting cells via the scavenger receptor A (CD91) (up-regulated in this study), and the antigen may then be presented by the APC in a process called cross-presentation (Schild and Rammensee 2000; Berwin et al. 2003). Furthermore, gp96 also induces CD80, CD86 and IL-12 production by binding to CD91 (Abbas AND Sharpe 2005). One intriguing possibility is that astrocytes can not only present antigens to activated $\mathrm{CD}^{+} \mathrm{T}$ cells, but that they can also activate microglia or dendritic cells to up-regulate costimulatory molecules and supply them with antigens via gp96. Indeed, this would fit well with the notion that dendritic cells and/or microglia are the primary cells responsible for initiating $\mathrm{CD} 4^{+} \mathrm{T}$-cell activation in experimental autoimmune encephalomyelitis (Greter et al. 2005; Heppner et al. 2005).

A further functional domain evident from our analysis is the role of astrocytes in the regulation of cell entry into the brain. It appears that in a disease situation, astrocytes turn from being 'guardians of the blood-brain barrier' towards cytokine-mediated opening of the BBB. This may occur via release of MCP-1 (CCL2) or up-regulation of proteases such as UPA and MMPs, and down-regulation of negative modulators such as TIMPs, as suggested by our study and previous functional data (Kataoka et al. 2000; Ferrari et al. 2004; Stamatovic et al. 2005). When the BBB is breached, T cells migrate into the brain via endothelial expression of adhesion molecules, but it has been suggested that VCAM-1 expression on astrocytes, as observed here, is essential for the migration of encephalitogenic $\mathrm{T}$ cells into the brain parenchyma to initiate experimental autoimmune encephalomyelitis (Gimenez et al. 2004). The most striking regulations we observed with respect to cell attraction were those of some chemokines. The massive release of these mediators enables attraction of most kinds of blood-borne immune cells, and affects the activation state and survival of neurones, astrocytes and microglia (Ambrosini AND Aloisi 2004). In addition, chemokines found here to be highly regulated, such as RANTES (CCL5) or MIP-1 $\beta$ (CCL4), have a variety of other pathogenic roles such as facilitation of pain via activation of CCR3 or CCR1. Therefore, chemokine expression (CCL5) was confirmed here, also on protein level, by ELISA. In addition, we have shown previously that IL-6, COX-2, iNOS and CD95 are regulated on the protein level, and we provided evidence that some of these regulations have functional implications as astrocytes become susceptible to CD95-mediated apoptosis after cytokine activation (Falsig et al. 2004a,c). 
(a)
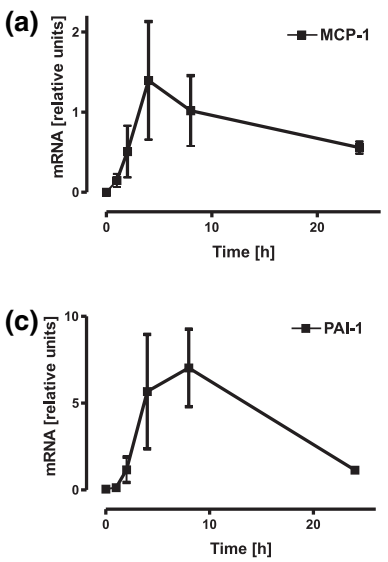

(e)

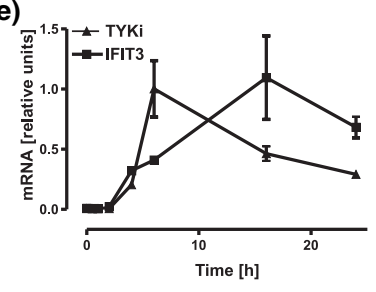

(b)

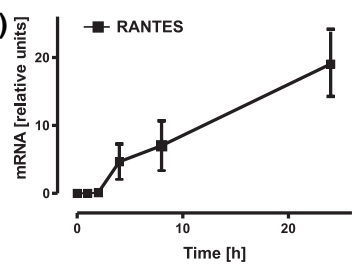

(d)

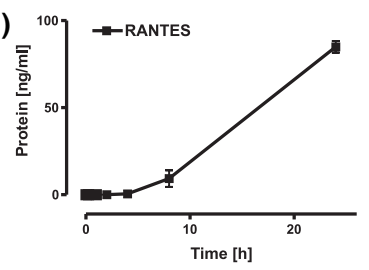

(f)

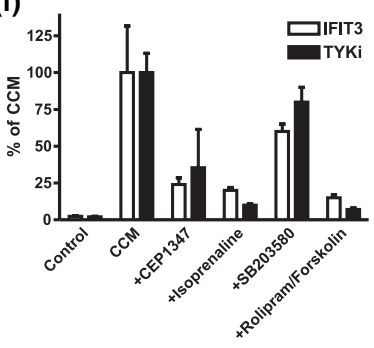

Fig. 10 Confirmation of gene regulations by an alternative analytical approach. Cells were stimulated with CCM for the times indicated. $(a-c),(e, f)$ Total RNA was extracted and mRNA was quantified by real-time RT-PCR. (d) Supernatant fluids were collected and analysed by ELISA for RANTES. (f) Total RNA was extracted from cells stimulated with CCM for $16 \mathrm{~h}$ after 30 min pre-treatment with CEP1347 $(100 \mathrm{nM})$, SB203580 $(5 \mu \mathrm{M})$, isoprenaline $(1 \mu \mathrm{M})$ or rolipram $(10 \mu \mathrm{M})$ plus forskolin $(1 \mu \mathrm{M})$. All data are displayed as means \pm SD with $n=3$ for pharmacological treatment and $n=6$ for CCM.

One observation that has also been reported by others is that microarray technology in general has a smaller dynamic range than PCR analysis. Most of the regulated genes confirmed by Q-PCR show a larger fold regulation (and sensitivity) when measured by PCR than by oligonucleotide hybridization analysis. Our own Q-PCR confirmation of birc1/2/3, bid, cd-95, upa, cflip, cox-2 and inos regulation has been published elsewhere (Falsig et al. 2004a,c) and here, we confirmed the regulation of $m c p-1$, rantes and pai-1 mRNA. Since all the regulations identified by chip analysis and subsequently evaluated by PCR were confirmed, we believe that our selected cut-off ratios are rather conservative and reflect real changes in mRNA expression.

In this context, it is important to note that the experimental window of the proteomics experiment is different from that of the array experiment. The criteria for protein detection were mostly based on a biochemical rationale: the use of a $\mathrm{pI}$ range of 4-10 in standard IEF/SDS gels without particular enrichment of a subcellular fraction, and a molecular weight cut-off of approximately $15-20 \mathrm{kDa}$. These conditions

deplete most of the membrane proteins and cytokines. A further apparent mismatch between proteomic and genomic analysis is expected from the fact that due to extensive posttranslational modifications, such as phosphorylation and functional proteolytic processing, a single cDNA spot on an array can evolve into dozens or even hundreds of molecular protein species (Schrattenholz 2004). It also has to be noted that we quantified mRNA regulation after 4 and $16 \mathrm{~h}$, while protein data were obtained after $24 \mathrm{~h}$ of CCM stimulation. Indeed, out of the 17 identified proteins ( 15 of which were present on our custom spotted array), only nine were significantly up-regulated. One protein, alpha enolase, was significantly up-regulated on the protein level while it was down-regulated on the mRNA level. This may be due to a mismatch of transcription and translation due to posttranscriptional events that are common for intermediary metabolism proteins.

Nevertheless, the few proteins identified here confirm some of the major themes evident from the transcriptional regulation, i.e. proteasomal processing (PA28 $\alpha$, PA28 $\beta$, SUG1) and a cellular response to viral or bacterial infections (Interferon-inducible GTPase, TYKi and IFIT3) (Fig. 1b). Notably, TYKi, IFIT3, ARP2/3 subunit 5, gp96 and CLIC4 protein have, to our knowledge, not been associated with astrocyte activation before, and the up-regulation of TYKi and IFIT3 on the protein level, as well as their pharmacological modulation on the RNA level, appear to be a new finding. Our study provides a picture of the activation dynamics of murine astrocytes in vitro. For a better in vivo understanding, good histological markers are essential. The currently most used astrocyte activation indicator is the immunoreactivity of the cytoskeletal protein, GFAP. Information on how marker expression correlates with different activation states is extremely scarce or confusing. Notably, we observed a down-regulation of the astrocyte activation marker GFAP (which was also reported by John et al. 2002) on the mRNA level despite the fact that we can extract more GFAP protein from activated astrocytes in vitro (Falsig et al. 2004a). GFAP staining (or in situ hybridization for other markers) in vivo also only marks sub-populations of astrocytes (Babcock et al. 2003). Thus, there is a need for additional markers to characterize various activation states and sub-populations of astrocytes. The requirement for a good histological inflammation marker would be a nonsecreted cytosolic or membrane-bound protein not expressed under resting conditions. In this study, using an artificial approximation of an inflammatory situation, we have identified three promising candidates, IFIT3, TYKi and Interferon-inducible GTPase, which all changed from almost undetectable to highly expressed levels (protein and RNA). These potential markers need to be verified in vivo for the expression in other cell types, for their up-regulation in various disease models and for their role in the inflammatory process itself. Any progress here will further our 
understanding of the astrocyte contribution to the pathogenesis of inflammatory and neurodegenerative diseases, such as multiple sclerosis, paraneoplastic neurological degenerations or Alzheimer's disease.

\section{Acknowledgements}

We gratefully acknowledge the excellent technical assistance and input of Andreas Rassov and Kirsten Olesen. Søren W. Rasmussen and SEQtools (http://www.seqtools.dk/) provided invaluable support for the design, manufacturing and management of our microarrays. We are furthermore indebted to Drs Jan T. Petersen, Søren Christensen, Jens Gerwien, Johan van Beek, Julie Lotharius, Kenneth Thirstrup and Jan Egebjerg for valuable contributions and insightful discussions during the course of this work.

\section{Supplementary material}

The following supplementary material is available for this article online:

Figure S1. Complete list of 'landscape' proteins of resting astrocytes. The table lists proteins identified by proteomic analysis of random spots, representing a selection of the most abundant proteins expressed in astrocytes. The proteins are grouped functionally with protein names, synonyms and protein accession number. Regulated proteins identified in this study have been included in the list, but are highlighted in grey boxes for clarity. Protein information is available at http://www.ncbi.nlm.nih.gov/ entrez/.

Figure S2. Complete list of genes analysed. The table lists all genes (with their respective accession numbers) that are represented by a 50-mere oligonucleotide on our microarray. Furthermore, we list the location of each oligo on our master plates (MTP) and their grid position on the microarray, as defined by four co-ordinates: mega row (MR), mega column (MC), sub row (SR) and sub column (SC). Gene information is available at http://www.ncbi.nlm.nih.gov/ entrez/.

This material is available as part of the online article from http:// www.blackwell-synergy.com

\section{References}

Abbas A. K. and Sharpe A. H. (2005) Dendritic cells giveth and taketh away. Nat. Immunol. 6, 227-228.

Aktan F. (2004) iNOS-mediated nitric oxide production and its regulation. Life Sci. 75, 639-653.

Aloisi F. (2001) Immune function of microglia Glia 36, 165-179.

Ambrosini E. and Aloisi F. (2004) Chemokines and glial cells: a complex network in the central nervous system. Neurochem. Res. 29, $1017-1038$.

Babcock A. A., Kuziel W. A., Rivest S. and Owens T. (2003) Chemokine expression by glial cells directs leukocytes to sites of axonal injury in the CNS. J. Neurosci. 23, 7922-7930.

Bachoo R. M., Kim R. S., Ligon K. L. et al. (2004) Molecular diversity of astrocytes with implications for neurological disorders. Proc. Natl Acad. Sci. USA 101, 8384-8389.

Baker C. A. and Manuelidis L. (2003) Unique inflammatory RNA profiles of microglia in Creutzfeldt-Jakob disease. Proc. Natl Acad. Sci. USA 100, 675-679.
Berwin B., Hart J. P., Rice S., Gass C., Pizzo S. V., Post S. R. and Nicchitta C. V. (2003) Scavenger receptor-A mediates gp96/ GRP94 and calreticulin internalization by antigen-presenting cells. EMBO J. 22, 6127-6136.

Bezzi P., Domercq M., Brambilla L. et al. (2001) CXCR4-activated astrocyte glutamate release via TNF alpha: amplification by microglia triggers neurotoxicity. Nat. Neurosci. 4, 702-710.

Bush T. G., Puvanachandra N., Horner C. H., Polito A., Ostenfeld T., Svendsen C. N., Mucke L., Johnson M. H. and Sofroniew M. V. (1999) Leukocyte infiltration, neuronal degeneration, and neurite outgrowth after ablation of scar-forming, reactive astrocytes in adult transgenic mice. Neuron 23, 297-308.

Cahill M. A., Wozny W., Schwall G. et al. (2003) Analysis of relative isotopologue abundances for quantitative profiling of complex protein mixtures labelled with the acrylamide/D3-acrylamide alkylation tag system. Rapid Commun. Mass Spectrom. 17, 12831290.

Castano A., Herrera A. J., Cano J. and Machado A. (2002) The degenerative effect of a single intranigral injection of LPS on the dopaminergic system is prevented by dexamethasone, and not mimicked by rh-TNF-alpha, IL-1beta and IFN-gamma. J. Neurochem. 81, 150-157.

Eddleston M. and Mucke L. (1993) Molecular profile of reactive astrocytes - implications for their role in neurologic disease. Neuroscience 54, 15-36.

Falsig J., Latta M. and Leist M. (2004a) Defined inflammatory states in astrocytes: correlation with susceptibility towards CD95-driven apoptosis. J. Neurochem. 88, 181-193.

Falsig J., Pörzgen P., Lotharius J. and Leist M. (2004b) Specific modulation of astrocyte inflammation by inhibition of Mixed Lineage Kinases with CEP-1347. J. Immunol. 173, 2762-2770.

Falsig J., Pörzgen P. and Leist M. (2004c) Modification of apoptosisrelated genes and CD95 signaling in cytokine-treated astrocytes. Signal Transduction 1-2, 17-28.

Faulkner J. R., Herrmann J. E., Woo M. J., Tansey K. E., Doan N. B. and Sofroniew M. V. (2004) Reactive astrocytes protect tissue and preserve function after spinal cord injury. J. Neurosci. 24, 21432155.

Ferrari C. C., Depino A. M., Prada F., Muraro N., Campbell S., Podhajcer O., Perry V. H., Anthony D. C. and Pitossi F. J. (2004) Reversible demyelination, blood-brain barrier breakdown, and pronounced neutrophil recruitment induced by chronic IL-1 expression in the brain. Am. J. Pathol. 165, 1827-1837.

Flo T. H., Smith K. D., Sato S., Rodriguez D. J., Holmes M. A., Strong R. K., Akira S. and Aderem A. (2004) Lipocalin 2 mediates an innate immune response to bacterial infection by sequestrating iron. Nature 432, 917-921.

Fontana A., Fierz W. and Wekerle H. (1984) Astrocytes present myelin basic protein to encephalitogenic T-cell lines. Nature 307, 273276.

Gimenez M. A., Sim J. E. and Russell J. H. (2004) TNFR1-dependent VCAM-1 expression by astrocytes exposes the CNS to destructive inflammation. J. Neuroimmunol. 151, 116-125.

Greter M., Heppner F. L., Lemos M. P., Odermatt B. M., Goebels N., Laufer T., Noelle R. J. and Becher B. (2005) Dendritic cells permit immune invasion of the CNS during experimental autoimmune encephalomyelitis. Nat. Med. 11, 328-334.

Hanisch U. K., Lyons S. A., Prinz M., Nolte C., Weber J. R., Kettenmann H. and Kirchhoff F. (1997) Mouse brain microglia express interleukin-15 and its multimeric receptor complex functionally coupled to Janus kinase activity. J. Biol. Chem. 272, $28853-28860$

Hedtjarn M., Mallard C., Eklind S., Gustafson-Brywe K. and Hagberg H. (2004) Global gene expression in the immature 
brain after hypoxia-ischemia. J. Cereb. Blood Flow Metab. 24, 1333-1351.

Heppner F. L., Greter M., Marino D. et al. (2005) Experimental autoimmune encephalomyelitis repressed by microglial paralysis. Nat. Med. 11, 146-152.

Hughes T. R., Mao M., Jones A. R. et al. (2001) Expression profiling using microarrays fabricated by an ink-jet oligonucleotide synthesizer. Nat. Biotechnol. 19, 342-347.

John G. R., Shankar S. L., Shafit-Zagardo B., Massimi A., Lee S. C., Raine C. S. and Brosnan C. F. (2002) Multiple sclerosis: re-expression of a developmental pathway that restricts oligodendrocyte maturation. Nat. Med. 8, 1115-1121.

John G. R., Lee S. C., Song X., Rivieccio M. and Brosnan C. F. (2005) IL-1-regulated responses in astrocytes: Relevance to injury and recovery. Glia $49,161-176$.

Kataoka K., Asai T., Taneda M., Ueshima S., Matsuo O., Kuroda R., Kawabata A. and Carmeliet P. (2000) Roles of urokinase type plasminogen activator in a brain stab wound. Brain Res. 887, 187190.

Kettenmann H. and Ransom B. R. (2004) Neuroglia, 2nd edn. Oxford University Press, Oxford.

Kim S. Y., Li J., Bentsman G., Brooks A. I. and Volsky D. J. (2004) Microarray analysis of changes in cellular gene expression induced by productive infection of primary human astrocytes: Implication for HAD. J. Neuroimmunol. 157, 17-26.

Knudsen S. (2002) A Biologist's Guide to Analysis of cDNA Microarray Data. Wiley Interscience, New York.

Ling H. and Recklies A. D. (2004) The chitinase 3-like protein human cartilage glycoprotein 39 inhibits cellular responses to the inflammatory cytokines interleukin-1 and tumour necrosis factor-alpha. Biochem. J. 380, 651-659.

MacMicking J. D. (2004) IFN-inducible GTPases and immunity to intracellular pathogens. Trends Immunol. 25, 601-609.

McGeer E. G. and McGeer P. L. (2003) Inflammatory processes in Alzheimer's disease. Prog. Neuropsychopharmacol. Biol. Psych. 27, 741-749.

Meeuwsen S., Persoon-Deen C., Bsibsi M., Ravid R. and Vaan Noort J. M. (2003) Cytokine, chemokine and growth factor gene profiling of cultured human astrocytes after exposure to proinflammatory stimuli. Glia 43, 243-253.

Neumann H., Medana I. M., Bauer J. and Lassmann H. (2002) Cytotoxic $\mathrm{T}$ lymphocytes in autoimmune and degenerative CNS diseases. Trends Neurosci. 25, 313-319.

Oberdorfer C., Adams O., MacKenzie C. R., De Groot C. J. and Daubener W. (2003) Role of IDO activation in anti-microbial defense in human native astrocytes. Adv. Exp. Med. Biol. 527, $15-26$.

Paglinawan R., Malipiero U., Schlapbach R., Frei K., Reith W. and Fontana A. (2003) TGFbeta directs gene expression of activated microglia to an anti-inflammatory phenotype strongly focusing on chemokine genes and cell migratory genes. Glia 44, 219-231.

Proescholdt M. A., Heiss J. D., Walbridge S., Muhlhauser J., Capogrossi M. C., Oldfield E. H. and Merrill M. J. (1999) Vascular endothelial growth factor (VEGF) modulates vascular permeability and inflammation in rat brain. J. Neuropathol. Exp. Neurol. 58, 613627.

Radhakrishnan S., Otte J., Enam S., Del Valle L., Khalili K. and Gordon J. (2003) JC virus-induced changes in cellular gene expression in primary human astrocytes. J. Virol. 77, 10 638-10 644.

Rivieccio M. A., John G. R., Song X., Suh H. S., Zhao Y., Lee S. C. and Brosnan C. F. (2005) The cytokine IL-1 beta activates IFN response factor 3 in human fetal astrocytes in culture. J. Immunol. 174, 3719-3726.

Roberts W. K. and Darnell R. B. (2004) Neuroimmunology of the paraneoplastic neurological degenerations. Curr. Opin. Immunol. 16, 616-622.

Saas P., Boucraut J., Quiquerez A. L., Schnuriger V., Perrin G., DesplatJego S., Bernard D., Walker P. R. and Dietrich P. Y. (1999) CD95 (Fas/Apo-1) as a receptor governing astrocyte apoptotic or inflammatory responses: a key role in brain inflammation? J. Immunol. 162, 2326-2333.

Saleh M., Vaillancourt J. P., Graham R. K. et al. (2004) Differential modulation of endotoxin responsiveness by human caspase-12 polymorphisms. Nature $\mathbf{4 2 9}, 75-79$.

Schild H. and Rammensee H. (2000) Gp96 - The immune system's Swiss army knife. Nat. Immunol. 1, 100-101.

Schrattenholz A. (2004) Proteomics: How to control highly dynamic patterns of millions of molecules and interpret changes correctly. Drug Discovery Today Technol. 1, 1-8.

Simonet W. S., Hughes T. M., Nguyen H. Q., Trebasky L. D., Danilenko D. M. and Medlock E. S. (1994) Long-term impaired neutrophil migration in mice overexpressing human interleukin-8. J. Clin. Invest. 94, 1310-1319.

Stamatovic S. M., Shakui P., Keep R. F., Moore B. B., Kunkel S. L., Van Rooijen N. and Andjelkovic A. V. (2005) Monocyte chemoattractant protein-1 regulation of blood-brain barrier permeability. J. Cereb. Blood Flow Metab. 25, 606.

Taylor G. A., Carballo E., Lee D. M. et al. (1996) A pathogenetic role for TNF alpha in the syndrome of cachexia, arthritis, and autoimmunity resulting from tristetraprolin (TTP) deficiency. Immunity 4, 445-454.

Vuong G. L., Weiss S. M., Kammer W., Priemer M., Vingron M., Nordheim A. and Cahill M. A. (2000) Improved sensitivity proteomics by postharvest alkylation and radioactive labelling of proteins. Electrophoresis 21, 2594-2605.

Weinstein E. (1997) Isolation and purification of primary rodent astrocytes, in Current Protocols in Neuroscience, pp. 3.5.1-3.5.9. John Wiley and Sons Inc., Indianapolis. 